\title{
Properties of an $\alpha_{s}$-casein-rich casein fraction: Influence of dialysis on surface properties, miscibility, and micelle formation
}

\author{
Anne Kessler, ${ }^{*}$ Orquidéa Menéndez-Aguirre,† Jörg Hinrichs, † Cosima Stubenrauch, $\ddagger$ and Jochen Weiss ${ }^{* 1}$ \\ *Department of Food Physics and Meat Science, Institute of Food Science and Biotechnology, University of Hohenheim, Garbenstraße 21/25, \\ 70599 Stuttgart, Germany \\ †Department of Dairy Science, Institute of Food Science and Biotechnology, University of Hohenheim, Garbenstraße 21, 70599 Stuttgart, \\ Germany \\ †Institut für Physikalische Chemie, Universität Stuttgart, Pfaffenwaldring 55, 70569 Stuttgart
}

\section{ABSTRACT}

In this study, the surface tension, miscibility, and particle size distribution of a solution containing an $\alpha_{\mathrm{s}}$-casein $(\mathrm{CN})$-rich $\mathrm{CN}$ fraction $\left(54 \mathrm{wt} \% \alpha_{\mathrm{s}}-\mathrm{CN}, 32 \mathrm{wt}\right.$ $\% \beta-\mathrm{CN}$, and $15 \mathrm{wt} \% \mathrm{k}-\mathrm{CN})$ were determined at $\mathrm{pH}$ 6.6. The nondialyzed $\mathrm{CN}$ fraction was compared with a dialyzed one. In the nondialyzed sample, every charge on the protein was compensated by 0.3 charges coming from counterions, whereas in the dialyzed sample, only 0.2 charges could be assigned to each charge on the protein. This relation was determined by calculating the charges at the proteins, taking the measured mineral content into account. The surface tension was measured as a function of the protein concentration by the du Noüy ring method at room temperature. Results indicated alterations in the surface properties after reduction of counterions. The equilibrium surface tension above the critical micelle concentration increased from $40.1 \times 10^{-3}$ to $45 \times 10^{-3} \mathrm{~N} / \mathrm{m}$, the critical micelle concentration increased from $0.9 \times 10^{-4}$ to $2 \times 10^{-3} \mathrm{~mol} / \mathrm{L}$, and the minimal area occupied per molecule at the surface increased from $2.4 \times 10^{-18}$ to $4.6 \times 10^{-18} \mathrm{~m}^{2}$. Cloud points were determined by measuring the absorbance of CN solutions as a function of the temperature. The cloud points were found to be concentration dependent and had a minimum at $0.2 \mathrm{wt}$ $\%$ at $34^{\circ} \mathrm{C}$ for nondialyzed $\mathrm{CN}$ and at $0.25 \mathrm{wt} \%$ at $28^{\circ} \mathrm{C}$ for dialyzed $\mathrm{CN}$, again demonstrating the influence of counterion reduction. Below the cloud point, a micellar phase was found to exist. The hydrodynamic diameter of the micelles were characterized by dynamic light scattering in both auto- and cross-correlation mode. However, no influence of reduction in counterions could be observed, possibly due to the fact that dynamic light scattering is not a suitable method for this type of system. The presence of self-assembled structures

Received March 11, 2013.

Accepted June 8, 2013.

${ }^{1}$ Corresponding author: j.weiss@uni-hohenheim.de was verified by freeze-fracture electron microscopy. The observed differences between dialyzed and nondialyzed samples were explained by changes in the counterion cloud surrounding the proteins. Consequently, the electrostatic interactions between as well as within the $\mathrm{CN}$ are altered by dialysis, which, in turn, affects the behavior at the surface as well as the properties in the solution.

Key words: $\alpha_{\mathrm{s}}$-casein, surface tension, clouding, selfassembled structure

\section{INTRODUCTION}

Historically, CN have been defined as the components that precipitate from milk when the $\mathrm{pH}$ is lowered to $\mathrm{pH}$ 4.6 (Fox, 2003). Caseins are a mixture of proteins; the 4 main components in bovine milk are $\alpha_{\mathrm{s} 1}-\mathrm{CN}$ with a concentration of $10.25 \mathrm{~g} / \mathrm{L}, \alpha_{\mathrm{s} 2}-\mathrm{CN}$ with a concentration of $2.75 \mathrm{~g} / \mathrm{L}, \beta-\mathrm{CN}$ with a concentration of $10.5 \mathrm{~g} / \mathrm{L}$, and $\kappa$-CN with a concentration of $3.5 \mathrm{~g} / \mathrm{L}$ (Creamer, 2004). Caseins have no secondary structure; consequently, they are very flexible and termed as rheomorphic (Holt and Lindsay, 1993). Because of their flexibility, the hydrophobic and hydrophilic residues are not buried inside the molecule. In consequence, $\mathrm{CN}$ are surface active (Fox, 2003). The adsorption of CN on hydrophobic surfaces has been much better understood after Dickinson et al. (1997a,b) applied the self-consistent field theory as a theoretical treatment. These calculations yielded an insight into the distribution of hydrophilic and hydrophobic domains. The investigations revealed that $\mathrm{CN}$ have molecular structures not unlike that of block copolymers. For example, $\beta-\mathrm{CN}$ has a diblock copolymer structure, with the C-terminal region exhibiting hydrophobic properties and the $\mathrm{N}$-terminal region exhibiting hydrophilic properties, whereas $\alpha_{\mathrm{s} 1}-\mathrm{CN}$ has a structure not unlike that of a triblock copolymer, with 2 hydrophobic ends and a hydrophilic middle (Horne, 2002).

In milk, $\mathrm{CN}$ are not present as single molecules, but they are associated in native $\mathrm{CN}$ micelles. A native 
CN micelle consists of $94 \%$ protein and $6 \%$ colloidal calcium phosphate. They are spherical in shape, with a diameter ranging from 50 to $500 \mathrm{~nm}$ and a mass ranging from $10^{6}$ to $3 \times 10^{9} \mathrm{Da}$, with a concentration of $10^{14}$ to $10^{16}$ micelles $/ \mathrm{mL}$ of milk. The structure of the CN micelle has yet not been fully resolved, but various models have been proposed (Fox, 2003).

Self-assembly of CN resulting in surfactant-like micelles takes part due to their amphiphilic properties (Horne, 2002). In the case of classical surfactants, selfassembly is well known and examined. Above the critical micelle concentration (CMC), micelles are formed in polar solvents, with the hydrophobic parts of the surfactants being oriented toward the interior of the micelle and the hydrophilic parts being in contact with the polar solvent to minimize the free energy of the system (Myers, 2006).

Micelles have shown to be very capable encapsulation systems, able to fortify foods, consisting mainly of water, with functional hydrophobic compounds. In addition, solubilization in micelles has led to protection of sensitive hydrophobic compounds and allowed for triggered release. Research is being carried out both in the structure design of such carrier systems (Zeeb et al., 2011, 2012; Gibis et al., 2012) as well as in the determination of their functional properties (Terjung et al., 2012).

In milk, the main task of $\mathrm{CN}$ is first and foremost to be a natural carrier of calcium and to provide essential amino acids to the neonate. As such, nature uses the CN micelle as a natural encapsulation system. For the food industry, it is therefore of considerable interest to take advantage of this natural encapsulation system and use it to encapsulate, carry, and deliver other functional compounds. Caseins can be used as carriers for several functional ingredients (Livney, 2010). For example, the native $\mathrm{CN}$ micelle can be treated chemically or by high pressure to encapsulate vitamin D (Semo et al., 2007; Menéndez-Aguirre et al., 2011; Haham et al., 2012) or curcumin (Sahu et al., 2008). Self-assembled structures of $\beta$-CN were shown to be appropriate carriers of anticancer drugs for oral administration (Shapira et al., 2010a,b,c, 2012; Bachar et al., 2012).

In the general context of developing an encapsulation system with a potential usage in food, we focused our investigations on previously published investigations by our collaborators in which a fully food-grade fraction consisting mainly of $\alpha_{\mathrm{s}}$-CN was derived using a scalable process (Post et al., 2009; Post and Hinrichs, 2011). Although the examined fraction was not a pure $\alpha_{\mathrm{s}} \mathrm{CN}$ isolate, we focused on the properties of this mixture, as examination of an $\alpha_{\mathrm{s}}$ - $\mathrm{CN}$ isolate would only have had scientific, but not industrial relevance. Moreover, influence of impurities in self-assembly is known to be important.

The objective of the study was to determine the temperature and concentration range where self-assembly of an $\alpha_{\mathrm{s}}$-CN-rich $\mathrm{CN}$ fraction takes place and to characterize the size of the self-assembled structures. Furthermore, the influence of reducing the mineral content with respect to the amount of ions counterbalancing the charges of the protein was examined. Therefore, CN samples were dialyzed, the surface properties were determined by surface tension measurements, the miscibility with water was determined by turbidity measurements, and, at the one-phase region, the self-assembled structures were characterized by dynamic light scattering. A comparison with nondialyzed samples were performed.

\section{MATERIALS AND METHODS}

\section{Fractionation of $\mathrm{CN}$}

Casein was fractioned by our collaborators (Department of Dairy Science and Technology, Institute of Food Science and Biotechnology, University of Hohenheim, Stuttgart, Germany) using a procedure described previously (Post et al., 2009). Instead of the $\beta$-CN-enriched solution, the $\alpha_{\mathrm{s}}$-CN-enriched precipitate was used and further purified. For the purification, a 3-step process (1-3; see below) was used: The precipitate was resolved (1) by adding $1 \mathrm{M} \mathrm{NaOH}$ (Carl Roth GmbH, Karlsruhe, Germany) until pH 7 (WTW series inoLab 720 $\mathrm{pH}$ meter, SenTix 41pH electrode; WTW, Weilheim, Germany) was reached. The CN was again precipitated (2) by adding $1 \mathrm{M} \mathrm{HCl}$ (Carl Roth $\mathrm{GmbH}$ ) to the cooled CN solution [temperature $(\boldsymbol{\vartheta})=2^{\circ} \mathrm{C}$ ] until $\mathrm{pH} 4.6$ was reached. The precipitate was separated (3) by centrifugation $\left(3,000 \times g\right.$ for $10 \mathrm{~min}$ at $4^{\circ} \mathrm{C}$; Heraeus Sepatech Biofuge 28RS; Heraeus, Hanau, Germany). This 3-step process was repeated once. The resolved (1) $\alpha_{\mathrm{s}}$-CN-rich CN fraction was then freeze dried (Lyovac GT4 04450; Leibold-Heraeus GmbH, Köln, Germany).

\section{Preparation of the CN Solutions}

The preparation of rehydrated nondialyzed and dialyzed $\alpha_{\mathrm{s}}-\mathrm{CN}$ is shown in Figure 1. Casein powder was dispersed in $20 \mathrm{mM}$ imidazole buffer (Carl Roth $\mathrm{GmbH})$ at $\mathrm{pH} 6.6$ at a concentration of $3 \mathrm{wt} \% \mathrm{CN}$. The system was stirred for at least $4 \mathrm{~h}$ and stored overnight to ensure complete hydration. After centrifugation $\left(19,700 \times g\right.$ for $30 \mathrm{~min}$ at $\left.20^{\circ} \mathrm{C}\right)$ the system was filtered with a folded filter $(595$ 1/2, $110 \mathrm{~mm}$ diameter; Whatman Ltd., Maidstone, UK; filtration 1) and a mi- 
crofilter (glass microfiber filters GF/F; Whatman Ltd.; filtration 2) to remove big agglomerates. To prepare the dialyzed $\mathrm{CN}$, the protein was dialyzed for $72 \mathrm{~h}$ with a cellulose ester dialysis membrane (MWCO 100-5,000, Spectra/Por Biotech; Spectrum Laboratories Inc. Rancho Dominguez, CA) against buffer. Diluted systems were prepared by adding buffer weight by weight to the stock solution. For particle size measurements, the solutions where filtered with syringe filters $(0.02 \mu \mathrm{m}$ of regenerated cellulose, Rotilabo; Carl Roth GmbH; filtration 3); 0.03 wt \% sodium azide (Carl Roth $\mathrm{GmbH}$ ) was added to all solutions to avoid microbial contamination. Double-distilled water with a conductivity of $0.03 \mathrm{mS} / \mathrm{cm}$ was used.

\section{Composition of the CN Fraction}

The overall protein content was calculated from the nitrogen content using the standard factor for milk proteins (i.e., 6.38). The nitrogen content was determined by the Dumas method (LECO FP-528; Leco Instruments GmbH, Mönchengladbach, Germany). The CN concentration and the fraction of the single $\mathrm{CN}$ were determined by reversed-phase HPLC (Post et al., 2009).

Ash content as a measure for mineral concentration was determined by incineration (BVL, 1980). Because the method was described for samples with low water content, samples were subjected to a drying chamber at $85^{\circ} \mathrm{C}$ before analysis (ULM400; Memmert GmbH \& Co. KG, Schwabach, Germany). To determine the content of individual minerals, the ash was dissolved in $1 \mathrm{~mol} / \mathrm{L}$ nitric acid (Carl Roth $\mathrm{GmbH}$ ). The concentrations of sodium, calcium, and phosphate were determined by inductively coupled plasma atomic emission spectroscopy (VDLUFA, 2011a) with radial view on the flame on a plasma power of $1.1 \mathrm{~kW}$ (ICP-OES Vista Pro; Varian, Belrose, Australia). The sample was fed in the argon plasma flame by a pneumatic nebulizer (cyclone spray chamber; SpecTec GmbH, Erding, Germany). The measurement was performed against an external calibration standard. The concentration of chloride was determined by ion chromatography (VDLUFA, 2011b).

\section{Surface Tension Measurements}

The surface tension of the samples was measured using the du Noüy ring method (STA-1; Sinterface Technologies, Dr. Reinhard Miller \& Dr. Alexander Makievski GbR, Berlin, Germany, equipped with an analytical balance; Sartorius CP64; Sartorius AG, Göttingen, Germany). Before each measurement, the surface tension of water was measured to ensure that the ring and the vessel were surfactant free. Surface tension was recorded as function of time. Corrections

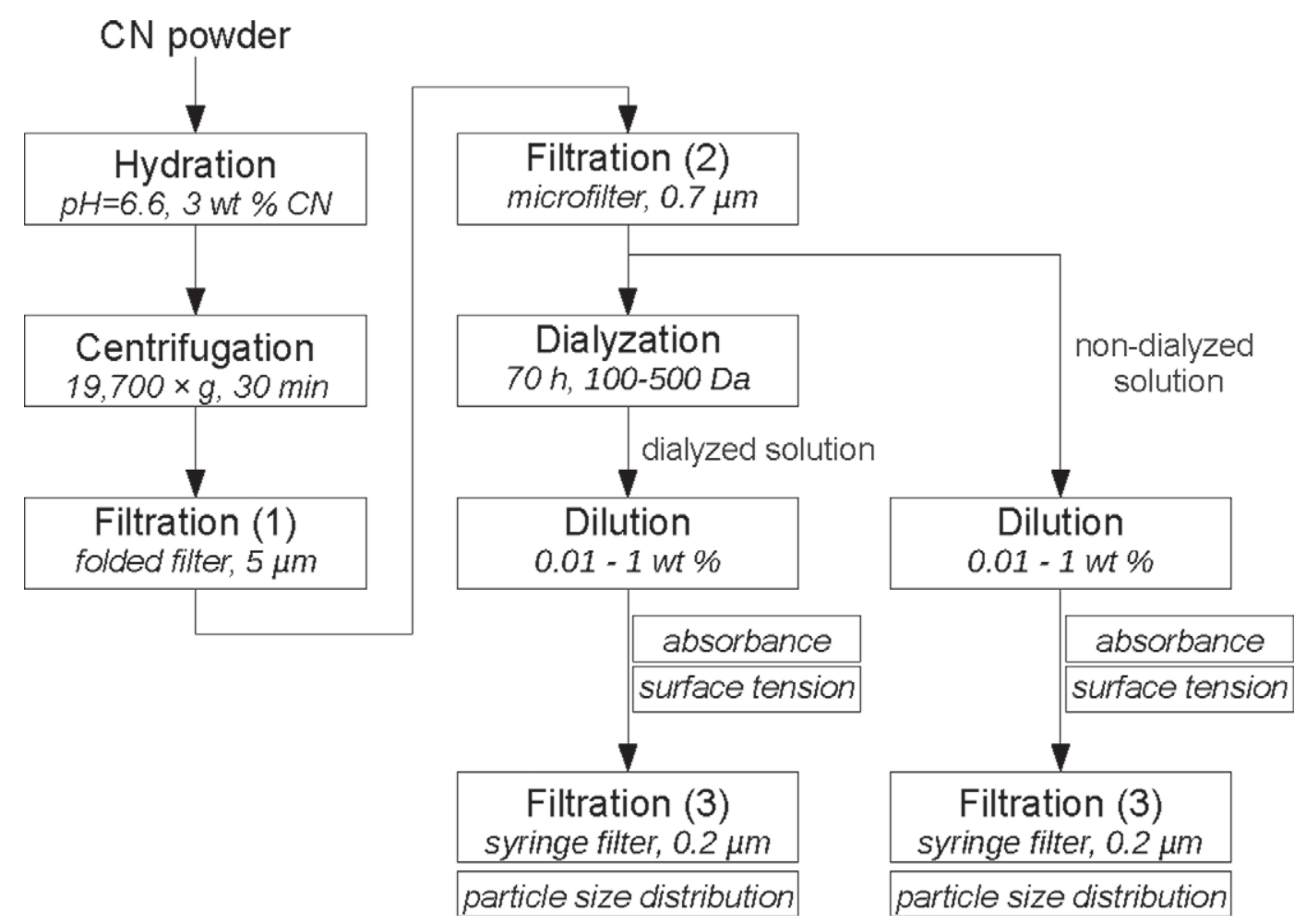

Figure 1. The preparation of dialyzed and nondialyzed casein solutions out of the $\alpha_{\mathrm{s}}$-CN and performed measurements. 
according to Harkins and Jordan (1930) were used. The surface tension of water was determined as $71.41 \pm$ $0.05 \times 10^{-3} \mathrm{~N} / \mathrm{m}$ at $22^{\circ} \mathrm{C}$, which is in agreement with values from the literature (Lide, 2003). Calculating the equilibrium surface tension and fitting the Gibbs equation were done with Matlab (version 6.0; MathWorks Inc., Natick, MA).

\section{Turbidity Measurements}

To determine the turbidity of solutions, the absorbance was measured with a photometer (8435; Hewlett-Packard Development Co. LP, Palo Alto, CA) at $400 \mathrm{~nm}$ as a function of the temperature. To this purpose, the photometer was equipped with a water bath (Julabo EH; Julabo GmbH, Seelbach, Germany) and a thermometer (GMH 3710 high precision digital thermometer; Greisinger Electronic GmbH, Regenstauf, Germany) with a PT100 probe (GTF 401, 1/10 DIN; Greisinger Electronic GmbH) to determine the temperature during the measurement. Disposable polystyrene cuvettes (Brand GmbH + Co. KG, Wertheim, Germany) were used. Before the measurement was conducted, a thermal equilibration time of 30 min was used at each temperature.

\section{Observation with Cross-Polarizers}

The possible formation of a liquid crystalline phase was identified by observing the samples with crosspolarizers (Polfilter linear ES49; Heliopan LichtfilterTechnik Summer GmbH \& Co. KG, Gräfelfing, Germany) at the temperatures where the turbidity measurements were performed. To this purpose, the sample was heated up in an aquarium equipped with a heating unit (Julabo MA; Julabo GmbH) and a thermometer.

\section{Determination of Particle Size Distribution}

The particle size distribution was determined by dynamic light scattering as a function of the temperature in the 1-phase region. The samples were filtered as previously described and equilibrated at least $10 \mathrm{~min}$ in the sample cell to ensure a uniform temperature. The measurement itself was performed with 2 different machines. The light source of both machines was a helium-neon laser with a wavelength of $633 \mathrm{~nm}$.

Instrument 1 was the Zetasizer Nano Series (Malvern Instruments GmbH, Herrenberg, Germany), which determines the autocorrelation function at a measuring angle of $173^{\circ}$ (backscattering). Disposable polystyrene cuvettes were used. Attenuator, cuvette position, measurement time, and number of correlation functions were selected automatically. The correlation functions were fitted by general purpose mode as implemented in the software to determine the diffusion coefficient.

As a second device (instrument 2), a 3D LS Spectrometer Pro (LS Instruments AG, Fribourg, Switzerland), determining a cross-correlation function at a measurement angle of $90^{\circ}$, was used. Tubes (disposable culture tubes, borosilicate glass; Fisher Scientific, Schwerte, Germany) were used as cuvettes. Each correlation function was fitted by CONTIN as implemented in the software to determine the diffusion coefficients.

In both cases, the hydrodynamic diameter $\left(d_{h}\right)$ was calculated by the Stokes-Einstein equation. For the calculations, the viscosity of water at respective temperatures was used.

\section{Determination of $\zeta$-Potential}

In addition to the determination of the particle size, a Zetasizer Nano analyzer (Malvern Instruments $\mathrm{GmbH}$ ) was also used to determine the $\zeta$-potential of the samples. The samples were filtered as previously described and where loaded in the cuvette (disposable folded capillary cell; Malvern Instruments $\mathrm{GmbH}$ ). The samples were equilibrated at least $10 \mathrm{~min}$ in the sample cell to ensure uniform temperature. Attenuator, voltage, measurement time, and number of measurements used to determine the electrophoretic mobility were selected automatically. By use of the Henry equation and Smoluchowski approximation, the $\zeta$-potential was calculated using the determined electrophoretic mobility (Teubner, 1981). Viscosity, refractive index and dielectric constant of water at measurement temperature were used.

\section{Freeze-Fracture Electron Microscopy}

Self-assembled aggregates were imaged by freezefracture electron microscopy (FFEM; Burauer et al., 2003). A freeze-fracture apparatus (EM BAF 060; Leica Microsystems GmbH, Wetzlar, Germany) and a transmission electron microscope (Tecnai G2 Sphera; FEI Co., Hillsboro, OR) were used.

\section{Cleaning of Used Glassware}

All used glassware were soaked in diluted deconex 11 universal solution (Borer Chemie AG, Zuchwil, Switzerland) overnight and rinsed afterward with doubledistilled water $(0.03 \mathrm{mS} / \mathrm{cm})$.

\section{Calculations and Statistical Analysis}

Calculations to determine the equilibrium surface tension, to fit the Gibbs equation, and to determine the 
cloud points were performed with Matlab (version 6.0; MathWorks Inc.). Turbidity, particle size distribution and $\zeta$-potential were repeated at least 3 times using duplicate samples. Means and standard errors for $95 \%$ confidence intervals $(P=95 \%)$ were calculated from these measurements using LibreOffice software (The Document Foundation, http://www.libreoffice.org).

Size distribution and $\zeta$-potential measurements were analyzed by multiple ANOVA and the differences were determined by a multiple comparison test performed with the statistics toolbox of Matlab (MathWorks Inc.) using a significance level of $\alpha=0.05$. As particle size distributions determined by dynamic light scattering had a log-normal distribution, the diameters were transferred to a normal distribution (Zar, 1999) before ANOVA and the multiple comparison tests were performed. Surface tension measurements for the storage experiment were repeated 3 times.

\section{RESULTS AND DISCUSSION}

\section{Composition of $\mathrm{CN}$}

The composition of the used $\alpha_{\mathrm{s}} \mathrm{C}$ CN-rich CN fraction, henceforth referred to as $\alpha_{s}-\mathrm{CN}$, is summarized in Table 1. Through fractionation and further purification, the $\alpha_{\mathrm{s}}-\mathrm{CN}$ content increased from $42.5 \mathrm{wt} \% \alpha_{\mathrm{s}}-\mathrm{CN}$ as in the raw material (Menéndez-Aguirre et al., 2011) to 54 wt \%. The used extraction process developed by Post et al. (2009) was carried out on a pilot scale and yielded a fully food-grade $\alpha_{s}-C N$ in suitable amounts, thereby allowing potential application in an industrial setting. To the best of our knowledge, no other method has previously been published with which a food-grade $\alpha_{\mathrm{s}}$-CN could be fractionated on a pilot scale, albeit the purity is not comparable with that of an $\alpha_{\mathrm{s}}-\mathrm{CN}$ isolate fractionated by ion-exchange chromatography (Menéndez et al., 2009).

Through the dialysis process, the overall mineral content of the solutions expressed as ash content, decreased by 49.3 wt \% from $0.3186 \pm 0.0020$ to 0.157 $\pm 0.006 \mathrm{~g} / 100 \mathrm{~g}$ of the $3 \mathrm{wt} \% \alpha_{\mathrm{s}} \mathrm{CN}$ solution in 20 $\times 10^{-3} \mathrm{~mol} / \mathrm{L}$ imidazole buffer. Minerals in $\mathrm{CN}$ were, on the one hand, minerals that were components of the amino acids, namely phosphate (phosphorylated serine and threonine) and sulfate (cysteine and methionine; Ng-Kwai-Hang, 2004) and, on the other hand, minerals that had been added during the purification process, namely calcium, sodium, and chloride (Post et al., 2009) and that, therefore, could be removed by the dialysis step. Specifically, the chloride content was reduced by 41 wt $\%$, the calcium content by 27 wt $\%$ and the sodium content by $35 \mathrm{wt} \%$. The reduction in overall mineral concentration was higher due to the fact that the determination of ash gathers the reduction in the amount of metal oxides, whereas the determination by atom emission spectroscopy only gathers the reduction of the single metals.

\section{Charge of Used CN}

In this section, we wanted to better understand on a theoretical level the influence of the number of ions present in the system on the charges of the protein both in the dialyzed and nondialyzed system. The estimated charge distributions of the amino acid residues at $\mathrm{pH}$ 6.6 are shown in Figure 2. For the deprotonated amino acid residues, the charge was estimated by

$$
z_{-}=\frac{A_{a}}{1+10^{\left(\mathrm{pk}_{\mathrm{a}}-\mathrm{pH}-\log \gamma\right)}}
$$

and for the protonated ones by

$$
z_{+}=\frac{A_{b}}{1+10^{\left(\mathrm{pH}-\mathrm{pk}_{\mathrm{a}}-\log \gamma\right)}}
$$

with $z$ being the amount of charged residues and $\mathrm{pk}_{\mathrm{a}}$ the acid constant (Mezdour et al., 2006). The activity $\gamma$ was estimated as 1 , a simplification that is admissible for dilute systems. The concentration of mole of amino acid per mole of protein $A_{a}$ respectively $A_{b}$ was set as 1 , as it was the charge of the single amino acid residues that was to be determined. The calculated net charge of the proteins, -24.9 for $\alpha_{\mathrm{s} 1^{-}} \mathrm{CN},-18$ for $\alpha_{\mathrm{s} 2^{-}}$ $\mathrm{CN},-9.3$ for $\beta-\mathrm{CN}$, and 1.3 for $\kappa-\mathrm{CN}$ corresponded to values given in the literature (Swaisgood, 2003). As illustrated in Figure 2, the calculation indicated that charges were not distributed uniformly over the protein sequence. Especially the phosphorylated serine residues

Table 1. Composition $( \pm \mathrm{SE})$ of $\alpha_{\mathrm{s}}-\mathrm{CN}$ powder

\begin{tabular}{lc}
\hline Item & Amount \\
\hline Protein composition & \\
Overall protein ${ }^{1}$ (g/g of powder) & $0.90 \pm 0.10$ \\
$\mathrm{CN}^{2}(\mathrm{~g} / \mathrm{g}$ of powder) & $0.689 \pm 0.013$ \\
$\alpha_{\mathrm{s}}-\mathrm{CN}$ (g/g of CN) & $0.539 \pm 0.013$ \\
$\beta-\mathrm{CN}$ (g/g of CN) & $0.318 \pm 0.011$ \\
$\kappa-\mathrm{CN}$ (g/g of CN) & $0.150 \pm 0.020$ \\
$\mathrm{Mineral} \mathrm{composition}_{\mathrm{Ash} \text { content }}$ (g/g of powder) & $0.0645 \pm 0.0009$ \\
$\mathrm{Ca}^{4}$ (g/g of powder) & 0.0024 \\
$\mathrm{Na}^{4}$ (g/g of powder) & 0.0067 \\
$\mathrm{Cl}^{4}$ (g/g of powder) & 0.0084 \\
\hline
\end{tabular}

${ }^{1}$ Determined by the Dumas method.

${ }^{2}$ Determined by HPLC.

${ }^{3}$ Determined through incineration.

${ }^{4}$ Composition determined by atomic emission spectroscopy. 


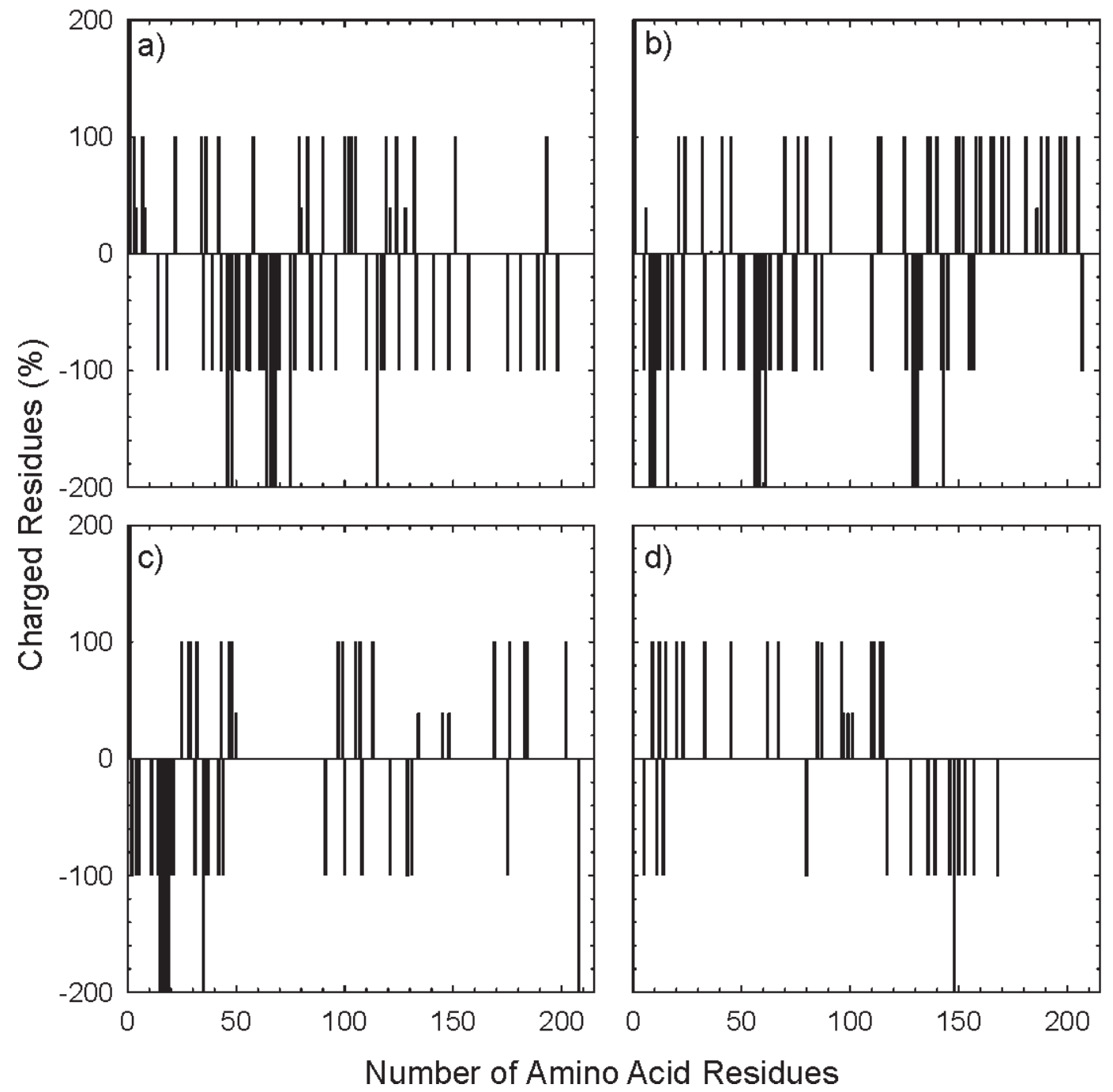

Figure 2. The estimated charge distributions of (a) $\alpha_{\mathrm{s} 1}-\mathrm{CN}$ B-8P, (b) $\alpha_{\mathrm{s} 2}-\mathrm{CN}$ A-11P, (c) $\beta-\mathrm{CN} \mathrm{A}{ }^{2}-5 \mathrm{P}$, and (d) $\kappa-\mathrm{CN}$ B-1P at pH 6.6 without added ions as a function of amino acid sequence. The calculations were based on a method proposed by Mezdour et al. (2006) by using the amino acid sequence of the named genetic types published by Ng-Kwai-Hang (2004) and the acid and basic dissociation constants published by Walstra (2003).

capable of being protonated induced highly charged regions. $\alpha_{\mathrm{s} 1}$-Casein had a very polar domain at residues 41 to 80 , whereas $\alpha_{\mathrm{s} 2}-\mathrm{CN}$ had 3 polar domains between AA 8 to 12, 56 to 63 , and 129 to 133 . $\beta$-Casein had a highly charged N-terminal domain, whereas $\kappa-\mathrm{CN}$ had a charged C-terminal region (Swaisgood, 2003).

The relationship of the charges at the protein to the determined ion content in solution was discussed above. Every charge of the CN in the nondialyzed sample was counterbalanced by 0.3 charges of counterions, whereas for the dialyzed CN, every charge was counterbalanced by 0.2 charges of counterions (Table 3 ). This was also apparent in the measured significant decrease of the $\zeta$-potential from -18 to $-23 \mathrm{mV}(\alpha=0.05)$ when a 3 wt \% CN solution was dialyzed. Counterions influence the molecules by screening electrostatic charges. Aside from steric and hydrophobic interactions, electrostatic interactions are responsible for the inter- and intramolecular conformation of the proteins. The influence of the above-described decrease of counterions by the dialysis step on measurable physical properties (e.g., surface tension clouding behavior and micelle formation), is described in the following sections.

\section{Surface Properties}

Surface tension was measured by the du Noüy ring method at concentrations between $10^{-3}$ and $10^{-7} \mathrm{~mol} / \mathrm{L}$ as function of time $t$, until an equilibrium value $\left(\bar{\gamma}_{\text {eq }}\right)$ was reached. The $\bar{\gamma}_{\text {eq }}$ values of dialyzed and nondia- 
Table 2. Characteristic parameters of dialyzed and nondialyzed $\alpha_{s^{-}}$ $\mathrm{CN}$ at the surface

\begin{tabular}{lcc}
\hline Item & $\begin{array}{c}\text { Nondialyzed } \\
\alpha_{\mathrm{s}}-\mathrm{CN}\end{array}$ & $\begin{array}{c}\text { Dialyzed } \\
\alpha_{\mathrm{s}}-\mathrm{CN}\end{array}$ \\
\hline $\mathrm{CMC}^{1}\left(10^{-4} \mathrm{~mol} / \mathrm{L}\right)$ & 0.9 & 2.0 \\
$\gamma_{\text {eq, }{ }_{3}{ }^{2}}{ }^{3}\left(10^{-3} \mathrm{~N} / \mathrm{m}\right)$ & 40.1 & 45.3 \\
$\Gamma_{\max }\left(10^{-7} \mathrm{~mol} / \mathrm{m}^{2}\right)$ & 7.0 & 3.6 \\
$A_{\min }{ }^{2}\left(10^{-18} \mathrm{~m}^{2}\right)$ & 2.4 & 4.6
\end{tabular}

${ }^{1}$ Critical micelle concentration.

${ }^{2}$ Averaged equilibrium surface tension at concentrations above the CMC.

${ }^{3}$ Maximum surface concentration, determined at the CMC.

${ }^{4}$ Minimal area occupied per molecule at the surface, determined at CMC.

lyzed $\mathrm{CN}$ are shown in Figure 3 as a function of the concentration. For the lowest examined concentration, $\bar{\gamma}_{\text {eq }}$ is lower than $\bar{\gamma}_{\text {eq }}$ of pure water due to highly surface active impurities. With increasing concentration, the surface tension of the $\mathrm{CN}$ decreases and finally reaches a plateau. Further increase in CN concentration causes no further decrease of the surface tension. After dialysis, the curve shifted to higher $\bar{\gamma}_{\text {eq }}$ values at equal concentrations. To calculate the CMC, the $\bar{\gamma}_{\text {eq }}$ values below the plateau were fitted with a polynomial of second order and the CMC was determined at the concentration at which the polynomial fit intersected the plateau, as shown in Figure 3.

In a second step, the fit was used to calculate the surface concentration $\Gamma$ and the minimum surface area $A_{\min }$ of $\mathrm{CN}$. The surface concentration $\Gamma$ was determined with the Gibbs isotherm for ionic surfactants (Hiemenz and Rajagopalan, 1997):

$$
\Gamma=-\frac{1}{2 R T}\left(\frac{\mathrm{d} \gamma_{\mathrm{eq}}}{\mathrm{d} \ln c}\right)_{p, T},
$$

where $R$ is the ideal gas constant, $p$ is the pressure, $T$ is the absolute temperature, and $c$ is the concentration. The area $A$ occupied by every molecule at the surface is given as

$$
A=\frac{1}{\Gamma \cdot N_{\mathrm{A}}}
$$

with the Avogadro constant $N_{\mathrm{A}}$ (Hiemenz and Rajagopalan, 1997). The maximal surface concentration $\Gamma_{\max }$ is reached at the $\mathrm{CMC}$, from which the minimum surface area $\left(A_{\min }\right)$ of a $\mathrm{CN}$ molecule can be calculated by

$$
A_{\min }=\frac{1}{\Gamma_{\max } \cdot N_{A}}
$$

The calculated values characterizing the surface properties of the examined CN are summarized in Table 2. After the dialysis with respect to the reduction of counterbalancing ions from 0.3 to 0.2 per charge at the $\mathrm{CN}$, the CMC increased from $0.9 \times 10^{-4}$ to $2 \times 10^{-4} \mathrm{~mol} / \mathrm{L}$, the minimum $\bar{\gamma}_{\text {eq }}\left(\bar{\gamma}_{\text {eq,min }}\right)$ value increased from $40.1 \times$ $10^{-3}$ to $45.3 \times 10^{-3} \mathrm{~N} / \mathrm{m}$, and the $A_{\min }$ value increased from $2.4 \times 10^{-18}$ to $4.6 \times 10^{-18} \mathrm{~m}^{2}$.

Comparing these results with those from the literature, it is apparent that $\bar{\gamma}_{\mathrm{eq}}(c)$ curves are in agreement with Latnikova et al. (2008) and Tripp et al. (1995) but differ from data reported by Krägel et al. (1999). Moreover, $\bar{\gamma}_{\text {eq,min }}$ values for $\beta$-CN are $52 \times 10^{-3} \mathrm{~N} / \mathrm{m}$ (Rodríguez Patino et al., 2003, 2006a,b; Sánchez et al., $2005,2006)$ as well as $49.4 \times 10^{-3}$ and $46.4 \times 10^{-3} \mathrm{~N} / \mathrm{m}$ (Rouimi et al., 2005) for 2 different CN. The $A_{\min }$ values reported in the literature are $7 \times 10^{-18} \mathrm{~m}^{2}$ (Makievski et al., 1998), $7.5 \times 10^{-18} \mathrm{~m}^{2}$ (Kotsmar et al., 2008), and $9.8 \times 10^{-18} \mathrm{~m}^{2}$ (Beaufils et al., 2007) for $\beta-\mathrm{CN}$, which are higher than the values determined here. The slightly different surface properties of $\mathrm{CN}$ described in the literature may, however, have been caused by differences in purity, source, and type of the examined $\mathrm{CN}$.

The strong influence of the dialysis process on the surface properties of the $\mathrm{CN}$ could be explained by the effects of the counterions on electrostatic interactions.

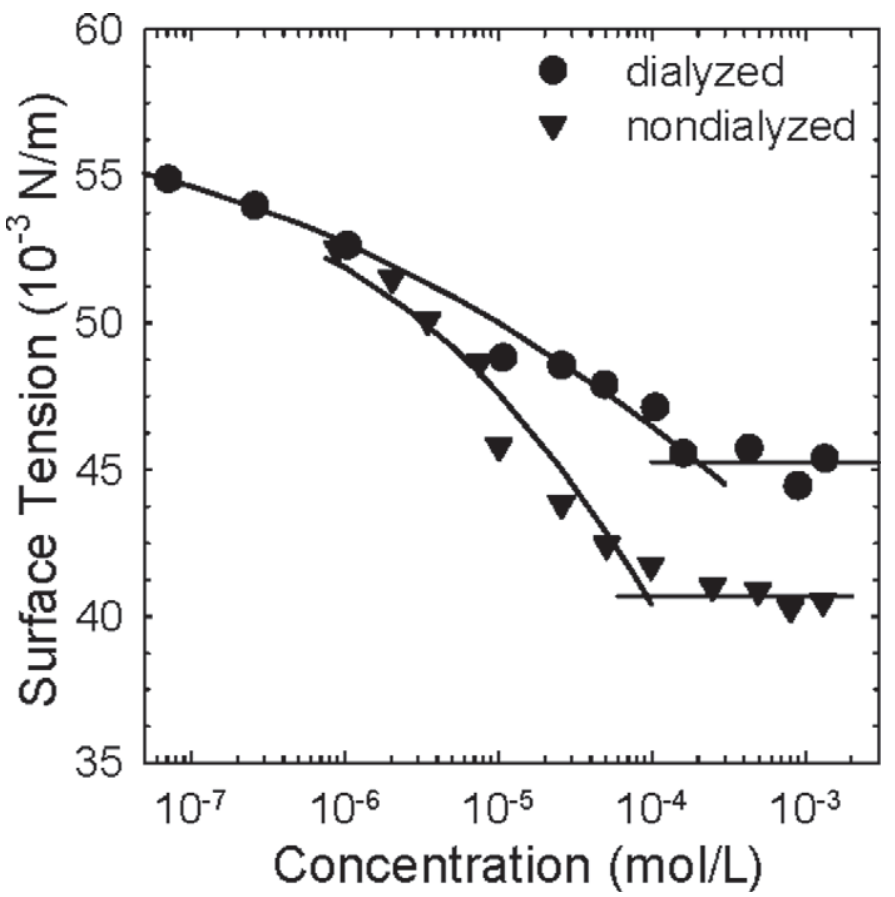

Figure 3. Equilibrium surface tension as a function of concentration of nondialyzed and dialyzed CN. Measured values are marked with symbols; fits are shown as lines. 
Table 3. Distribution of charges and $\zeta$-potential in nondialyzed and dialyzed $\alpha_{\mathrm{s}}$-CN solutions at $\mathrm{pH} 6.6$

\begin{tabular}{|c|c|c|c|c|}
\hline Item & $\begin{array}{l}\text { Positive } \\
\text { charge }\end{array}$ & $\begin{array}{l}\text { Negative } \\
\text { charge }\end{array}$ & $\begin{array}{l}\text { Net } \\
\text { charge }\end{array}$ & $\frac{{ }^{\zeta} \text { Potential }^{1}}{(\mathrm{mV})}$ \\
\hline \multicolumn{5}{|l|}{ Charged amino acid residues $^{2}$} \\
\hline$\alpha_{\mathrm{s} 1}-\mathrm{CN}\left(\mathrm{mol}^{-1}\right)$ & $7 \times 10^{20}$ & $2 \times 10^{21}$ & $-1 \times 10^{21}$ & - \\
\hline$\alpha_{\mathrm{s} 2^{2}}-\mathrm{CN}\left(\mathrm{mol}^{-1}\right)$ & $3 \times 10^{20}$ & $4 \times 10^{20}$ & $-1 \times 10^{20}$ & - \\
\hline$\beta-\mathrm{CN}\left(\mathrm{mol}^{-1}\right)$ & $5 \times 10^{20}$ & $7 \times 10^{20}$ & $-2 \times 10^{20}$ & - \\
\hline$\kappa-\mathrm{CN}\left(\mathrm{mol}^{-1}\right)$ & $3 \times 10^{20}$ & $2 \times 10^{20}$ & $+1 \times 10^{20}$ & - \\
\hline 3 wt $\%$ solution $\left(100 \mathrm{~g}^{-1}\right)$ & $2 \times 10^{21}$ & $3 \times 10^{21}$ & $-1 \times 10^{21}$ & - \\
\hline \multicolumn{5}{|c|}{ Counterions in 3 wt $\%$ solution $^{3}$} \\
\hline Nondialyzed $\left(100 \mathrm{~g}^{-1}\right)$ & $6.8 \times 10^{20}$ & $3.9 \times 10^{20}$ & $+2.9 \times 10^{20}$ & - \\
\hline Dialyzed $\left(100 \mathrm{~g}^{-1}\right)$ & $4.6 \times 10^{20}$ & $2.3 \times 10^{20}$ & $+2.3 \times 10^{20}$ & - \\
\hline \multicolumn{5}{|c|}{ Overall charge in $3 \mathrm{wt} \%$ solution } \\
\hline Nondialyzed $\left(100 \mathrm{~g}^{-1}\right)$ & $2.68 \times 10^{21}$ & $3.39 \times 10^{21}$ & $-7.1 \times 10^{20}$ & $-18 \pm 2^{\mathrm{a}}$ \\
\hline Dialyzed $\left(100 \mathrm{~g}^{-1}\right)$ & $2.46 \times 10^{21}$ & $3.23 \times 10^{21}$ & $-7.7 \times 10^{20}$ & $-23 \pm 5^{b}$ \\
\hline
\end{tabular}

\footnotetext{
${ }^{\mathrm{a}, \mathrm{b}}$ Means with different lowercase letters as superscripts indicate significant differences $(\alpha=0.05)$.

${ }^{1}$ Determined by measuring the electrophoretic mobility, average of 3 measurements $\pm \mathrm{SE}(P=95 \%)$.

${ }^{2}$ Calculations based on a method proposed by Mezdour et al. (2006) by using the amino acid sequence of the genetic types $\alpha_{s 1}-\mathrm{CN}$ B-8P, $\alpha_{s 2}-\mathrm{CN}$ A-11P, $\beta-\mathrm{CN} \mathrm{A}{ }^{2}-5 \mathrm{P}$, and $\kappa-\mathrm{CN}$ B-1P published by Ng-Kwai-Hang (2004) and the acid and basic dissociation constants published by Walstra (2003). Composition of $3 \mathrm{wt} \%$ solution as determined in Table 1, assuming an $\alpha_{\mathrm{s}}-\mathrm{CN}$ composition of $80 \% \alpha_{\mathrm{s} 1}-\mathrm{CN}$ and $20 \% \alpha_{\mathrm{s} 2}-\mathrm{CN}$.

${ }^{3}$ Based on analysis of minerals, assuming $\mathrm{Cl}^{-}$as carrier of negative charge and $\mathrm{Na}^{+}$and $\mathrm{Ca}^{2+}$ as carrier of positive charges; mineral composition determined in duplicate.
}

Because $A_{\min }$ increases after the dialysis, one could argue that either the protein unfolds or that the repulsive interactions between the molecules increase, both leading to a larger surface area. The same tendency was observed previously (Gažová et al., 1999) for cytochrome c, where an increase in $\bar{\gamma}_{\text {eq }}$ values was observed with decreasing $\mathrm{NaCl}$ concentration. Absorbance measurements showed that this was related to conformational changes in the molecule. Dickinson and Golding (1998) described the conformation changes of $\beta-\mathrm{CN}$ adsorbed at a hydrophobic surface by adding salt with a "blob-and-spring" model. Addition of salt leads to a compression of the spring and, as a consequence, to a more compact structure.

Lower CMC at higher ion concentrations, as observed here, were also reported for $\beta-\mathrm{CN}$ (Portnaya et al., 2006, 2008). Similarly to simple ionic surfactants (Schulze-Schlarmann et al., 2006), the ions decrease the electrostatic repulsion of the adsorbed molecules during adsorption, thereby increasing the adsorption tendency and thus the surface activity, which, in turn, lowers the CMC (Evans et al., 1970). Furthermore, it has been reported that an increase in the ion concentration leads to improved emulsifying and foaming properties of sodium caseinate (Mohanty et al., 1988), which could also be related to interfacial changes.

In conclusion, one can say that the decrease in the ion concentration by dialysis, namely reducing the amount of counterions from 0.3 to 0.2 per charge at the $\mathrm{CN}$, leads to altered adsorption properties and to conformational changes of the $\mathrm{CN}$ at the air/water surface and, consequently, to an increase in the CMC, $\bar{\gamma}_{\text {eq,min }}$, and $A_{\min }$, which is consistent with the results described in the literature.

\section{Long-Term Stability of $\alpha_{s}-C N$}

It is known that proteins undergo microbial and enzymatic degradation during storage, even if they are stored under cold conditions and in the presence of sodium azide. Because the dialysis required $3 \mathrm{~d}$, followed by a week required for the surface tension measurements, we wanted to assess whether degradation influenced the surface tension measurements. This was of particular importance in dialyzed samples, as these were generally somewhat older due to the longer duration of the preparation and analysis process. To this purpose, a dialyzed $\mathrm{CN}$ solution with a concentration of $2.6 \times 10^{-7} \mathrm{~mol} / \mathrm{L}$ was stored and the surface tension was measured at $\mathrm{d} 3,5$, and 7 after the dialysis. The results are shown in Figure 4; $\bar{\gamma}_{\text {eq,min }}$ was determined, with $\bar{\gamma}_{\text {eq,min }}=54.3 \pm 0.8 \times 10^{-3} \mathrm{~N} / \mathrm{m}$ at d $3, \bar{\gamma}_{\text {eq,min }}=$ $53.9 \pm 0.2 \times 10^{-3} \mathrm{~N} / \mathrm{m}$ at $\mathrm{d} 5$, and $\bar{\gamma}_{\text {eq,min }}=53.5 \pm 0.5$ $\times 10^{-3} \mathrm{~N} / \mathrm{m}$ at $\mathrm{d} 7$. Therefore, no significant influence of the storage time on $\bar{\gamma}_{\text {eq, min }}$ could be observed $(\alpha=$ 0.05). However, an influence of the storage time on the initial surface tension at $t=0\left(\gamma_{t=0}\right)$ could be observed, as seen in Figure $4 ; \gamma_{t=0}$ decreased significantly from 67 $\pm 3 \times 10^{-3} \mathrm{~N} / \mathrm{m}$ at $\mathrm{d} 3$ to $60 \pm 6 \times 10^{-3} \mathrm{~N} / \mathrm{m}$ at $\mathrm{d} 7(\alpha$ $=0.05)$. This means that with increasing storage time, additional surface-active molecules are produced. Possibly, these could be peptides that are formed by degradation of $\mathrm{CN}$ by enzymes that are naturally present or by microorganisms that could grow despite the added 
sodium azide. This assumption was supported by measurements of the overall CN content by HPLC and the protein content by the Dumas method. The amount of $\mathrm{CN} /$ protein decreased from 0.98 to $0.75 \mathrm{~g}$ of $\mathrm{CN} / \mathrm{g}$ of protein after the dialysis step. Thus, CN apparently degraded to form smaller protein fragments, which were only detected by the Dumas method. The formation of surface-active peptides from CN after addition of enzymes was also reported in the literature (Caessens et al., 1997, 1999a,b; Gangnard et al., 2007).

\section{Miscibility Gaps}

Figure 5 shows as an example a solution containing 0.5 wt $\%$ nondialyzed $\mathrm{CN}$ at 40 and $65^{\circ} \mathrm{C}$. At $40^{\circ} \mathrm{C}$, the $\mathrm{CN}$ solution had a clear and slightly yellow appearance, indicating complete miscibility of the $\mathrm{CN}$ with water. When heated, the sample suddenly became turbid (cloudy), as seen in Figure 5. The sudden turbidity increase indicates a phase separation and is caused by the formation of a finely dispersed second phase that scatters light. If this solution would be allowed to stand at $65^{\circ} \mathrm{C}$, the phases would separate. The presence of miscibility gaps is well known for aqueous mixtures of some weakly polar and most nonionic surfactants (Laughlin, 1994).

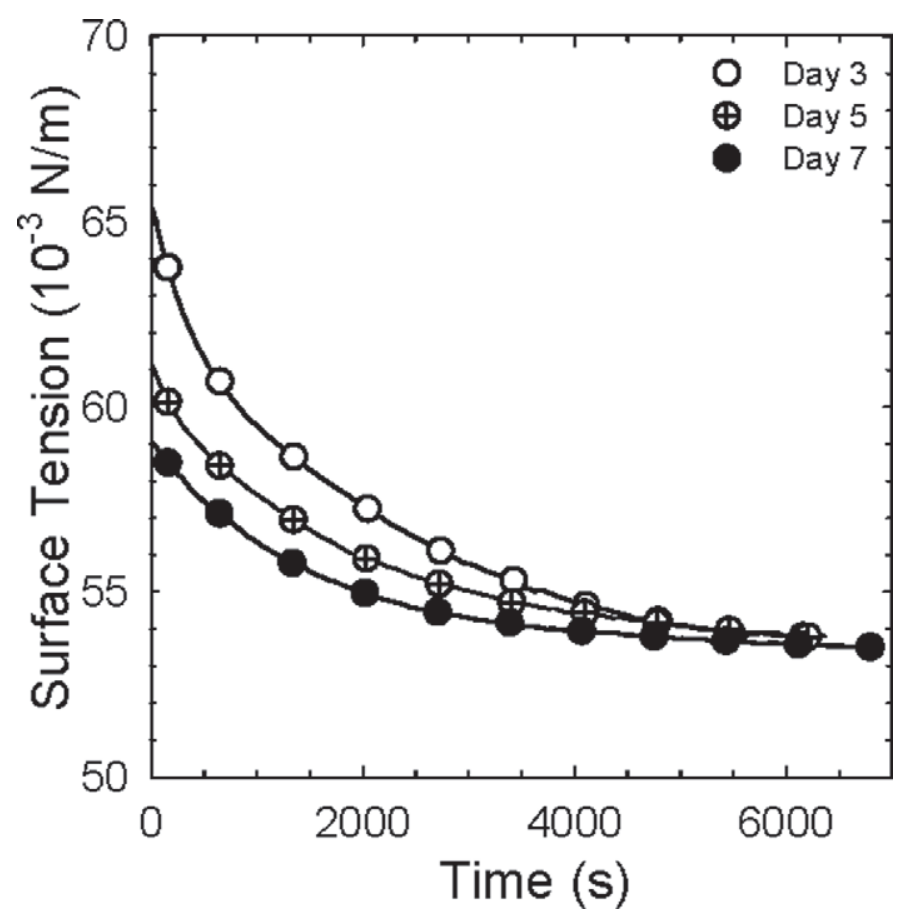

Figure 4. Dynamic surface tension as function of time $t$ of dialyzed CN solution with a concentration of $2.6 \times 10^{-7} \mathrm{~mol} / \mathrm{L}$ stored after dialyzing for 3,5 , and $7 \mathrm{~d}$. One representative result out of 3 measurements is shown; every tenth value is marked with a symbol.
To determine the temperature at which phase separation precisely occurred, the absorbance of the solution was measured as a function of the temperature as described in the literature (Asherie, 2004). Figure 5 shows the increase of the absorbance at $51^{\circ} \mathrm{C}$ from 0.2 to 4 at $400 \mathrm{~nm}$ for a solution containing $0.5 \mathrm{wt} \%$ nondialyzed $\mathrm{CN}$. This characteristic temperature, known as the cloud point $\left(\boldsymbol{\vartheta}_{\mathrm{cp}}\right)$, denotes the transition from a 1-phase to a 2-phase system. Below $\vartheta_{\text {cp }}$, any absorbance measured is caused by interaction of light with the dissolved $\mathrm{CN}$. In this region, the absorption followed the BeerLambert Law, further proof that CN were likely molecularly dispersed (for results, see Appendix Table A1). Above $\vartheta_{\text {cp }}$ the absorbance is caused by the finely dispersed second phase that scatters light, reducing the transmittance. The absorbance at the cloud point $\left(A_{\vartheta_{\mathrm{cp}}}\right)$ was defined as

$$
A_{\vartheta_{\mathrm{cp}}}=A_{\min }+0.05 \text { for } c>0.01 \mathrm{wt} \%
$$

and

$$
A_{\vartheta_{\mathrm{cp}}}=A_{\min }+0.01 \text { for } c=0.01 \text { wt } \%
$$

with $A_{\min }$ being the lowest observed absorbance; $\vartheta_{\text {cp }}$ was determined by linear interpolation of the measured absorbance as a function of the temperature. For samples with $c>0.01$ wt \%, a change of 0.05 was considered significant, whereas for $c=0.01 \mathrm{wt} \%$, a change of 0.01 was used to determine the onset of the phase separation.

We chose to measure the absorbance instead of determining the cloud points visually as usual, because the yellowish color of the $\mathrm{CN}$ solution made it difficult to detect changes in turbidity by the naked eye. We nevertheless also conducted a visual analysis of samples using a cross-polarizer to detect liquid crystalline phases. The presence of such phases could have led to an incorrect interpretation of the absorbance measurements. Although the possibility of liquid crystal formation has been reported in the literature (Euston and Horne, 2005), no liquid crystal was detected within the chosen temperature and concentration range. Therefore, the increased absorbance was only caused by the scattering of finely dispersed droplets that formed during phase separation.

The $\vartheta_{\text {cp }}$ are shown as a function of the CN concentration in Figure 6. One sees typical miscibility gaps with a lower critical point. The nondialyzed CN had a concentration-dependent clouding behavior with $\vartheta_{\mathrm{cp}}=$ $46^{\circ} \mathrm{C}$ at the lowest examined concentration $(0.01 \mathrm{wt} \%)$, a minimum at 0.2 wt $\%$ with $\vartheta_{\mathrm{cp}}=34^{\circ} \mathrm{C}$ (lower critical 
a)

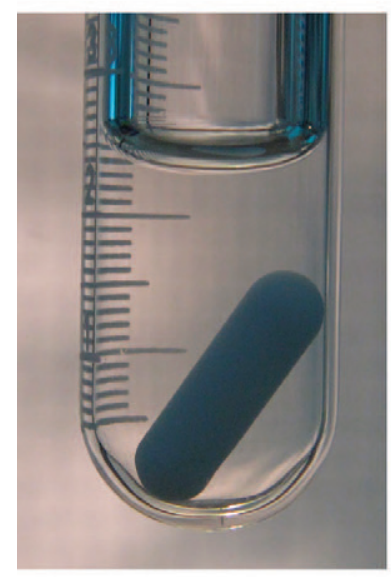

$\vartheta=40^{\circ} \mathrm{C}$

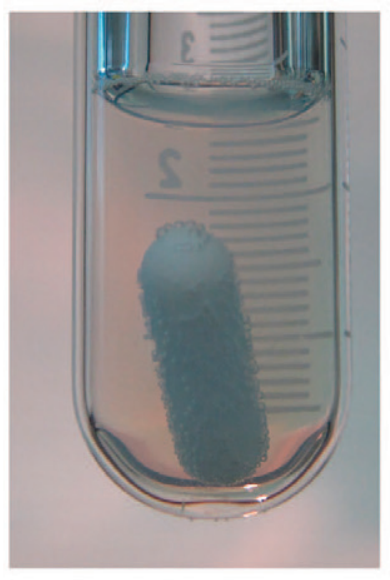

$\vartheta=65^{\circ} \mathrm{C}$

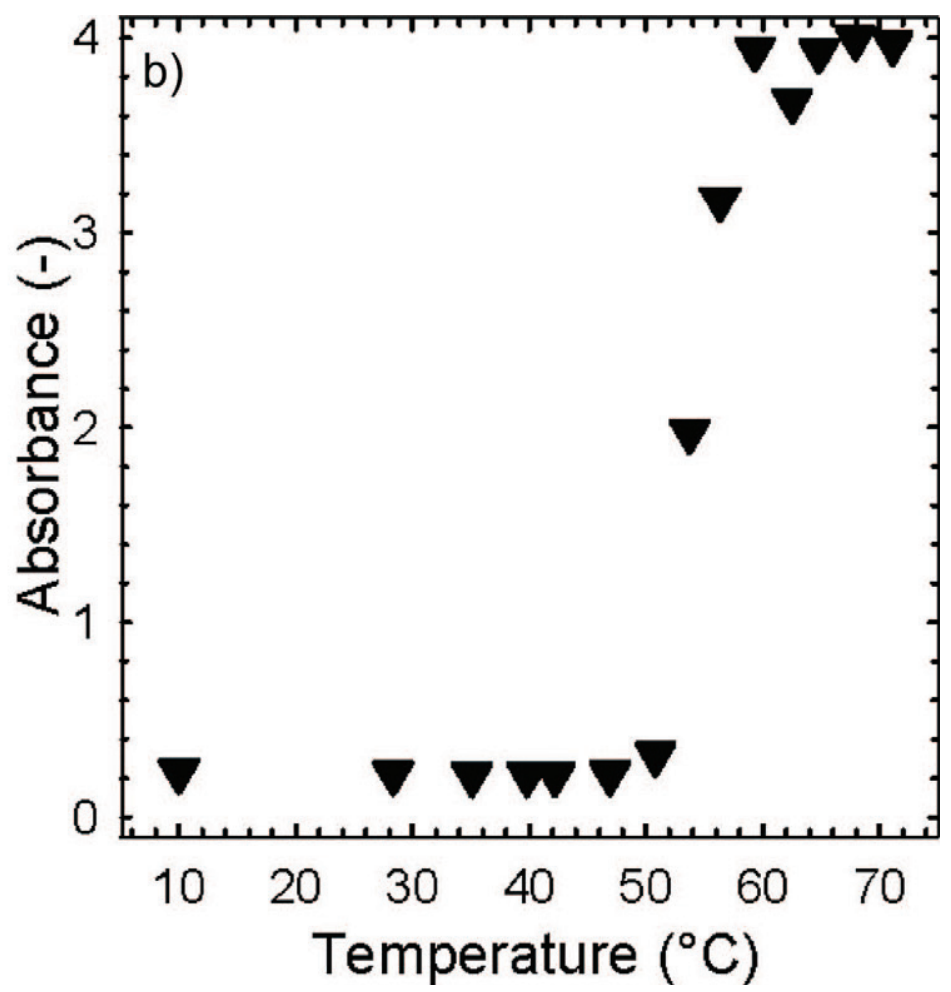

Figure 5. (a) Photos of a nondialyzed CN solution with a concentration of $0.5 \mathrm{wt} \%$ at a temperature $(\vartheta)$ of $40^{\circ} \mathrm{C}$ (below the cloud point) and at $65^{\circ} \mathrm{C}$ (above the cloud point) and (b) the absorbance of this solution as a function of temperature. Color version available in the online PDF.

point), and the highest value with $\vartheta_{\mathrm{cp}}=55^{\circ} \mathrm{C}$ at the highest examined concentration (1 wt \%). The dialyzed CN showed similar behavior but the miscibility gap was shifted to lower $\vartheta_{\text {cp }}$ values. For example, the $\vartheta_{\text {cp }}$ at 0.1 wt $\%$ was decreased from 34 to $28^{\circ} \mathrm{C}$ by dialysis with respect to reducing the amount of ions in solutions, counterbalancing the charges at the $\mathrm{CN}$ from 0.3 to 0.2 per charge at the proteins.

The observed increase in absorbance with increasing temperature and the influence of ions on protein solubility was also reported by Ye et al. (2012) for sodium caseinate solutions. An increasing solubility of sodium caseinate was found by the addition of trisodium citrate, disodium orthophosphate, tetrasodium pyrophosphate, and sodium hexametaphosphate at $\mathrm{pH}$ 5.8 (Mizuno and Lucey, 2005) and by addition of $\mathrm{NaCl}$ at $\mathrm{pH} 4$, pH 5 (Vieira et al., 2006), and $\mathrm{pH} 7$ (Ye et al., 2000). The solubility of $\alpha_{\mathrm{s}^{-}}$and $\beta-\mathrm{CN}$ appears to be also affected by the type and concentrations of buffers (Post et al., 2012). Moreover, cloud point (Grigsby et al., 2001; Lu et al., 2004; Park and Bae, 2004) and solubility (Ries-Kautt and Ducruix, 1989; Guilloteau et al., 1992) of the protein lysozyme were also altered by adding several salts.

Generally speaking, clouding is caused by dehydration of the hydrophilic part of a surfactant and forma-

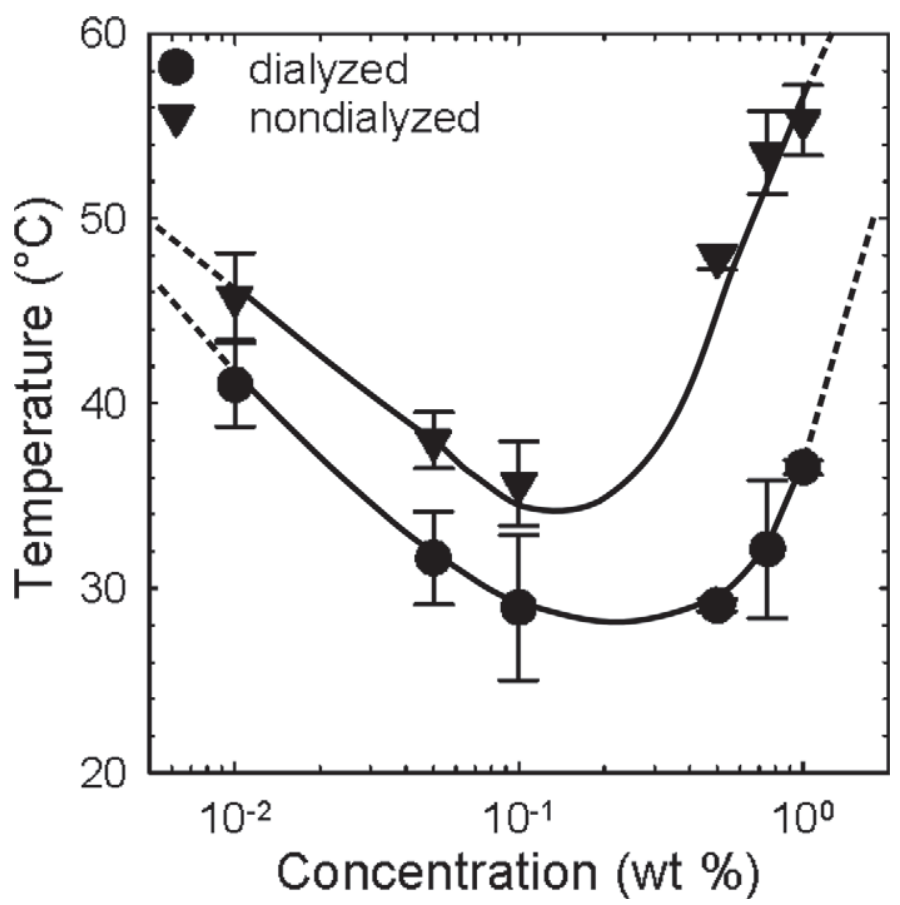

Figure 6. Miscibility gaps of dialyzed and nondialyzed CN solutions as a function of temperature and concentration. Lines are guides to the eye; average and SE $(P=95 \%)$ are given. 
tion of clusters of dehydrated surfactants (Mukherjee et al., 2011). To form a surfactant-rich phase, the sum of the interactions between the surfactants molecules must be attractive. In the case of proteins, electrostatic, steric, hydrophobic, and van der Waals interactions are present (Lu et al., 2004). Our results indicate that the sum of these interactions was repulsive below the cloud point and attractive above the cloud point and it was altered by removal of salts, leading to a decrease in $\vartheta_{\text {cp }}$.

The first detailed studies concerning the influence of salts on the solubility of proteins were done in 1880 by F. Hofmeister (Kunz et al., 2004). His experiments led to a classification of ions in kosmotropic and chaotropic ones, either enhancing or reducing the solubility of proteins. Recent studies showed that this classification also depends on the type of the protein. For example the lyotropic series of lysozyme was shown to have a reversed behavior (Ries-Kautt and Ducruix, 1989). An ongoing debate still exists as to how salts interact with proteins on a macromolecular scale and how this interaction is related to solubility. As highlighted by Ciferri (2008) in his review, ions have charge-dependent and charge-independent effects on proteins. Chargedependent effects are those related to the screening of protein charges by ions. These effects are ion specific and were described by the concept of K. D. Collins (Kunz, 2010), which assumes that ions are spheres with a point charge in their center. Small ions bind water molecules tightly (hard spheres), whereas large ions have a loosely bound hydration shell (soft spheres). Oppositely charged ions can bind only if both are either soft or hard spheres. Binding between soft and hard spheres is not possible. Charge-independent effects are those related to the interaction of groups with lower polarities on the proteins with their surrounding environment of water and salt (Ciferri, 2008). Both protein and salt require water to form hydration shells. At high ion and protein concentration, there is a lack of water molecules to form hydration shells around both substances. Under such conditions, the proteins may form a second phase with a higher density, thereby increasing the number of available water molecules that can hydrate the salt. This effect has, for example, led to increasing cloud points of lysozyme after addition of $\mathrm{Na}_{2} \mathrm{SO}_{4}$ and $\left(\mathrm{NH}_{4}\right)_{2} \mathrm{SO}_{4}$ (Grigsby et al., 2001).

One may thus conclude that the removal of ions from the examined $\mathrm{CN}$ caused several changes on the molecular level that in turn altered their solubility, which is in agreement with the literature. At the present time, we are not able to give an explanation on a macromolecular level. It appears, however, that the superposition of effects described above and the specific environmental conditions may have caused this behavior.

\section{Particle Size Distribution of Micelles Formed by $\alpha_{s}-C N$}

Surface tension measurements showed that the examined $\alpha_{\mathrm{s}}-\mathrm{CN}$ was surface active and had a CMC. Cloud point measurements over a specified temperature and concentration range were used to localize the 1-phase region. We thus concluded that $\alpha_{\mathrm{s}}-\mathrm{CN}$ forms self-assembled structures at distinct temperature/concentration ranges. The particle size distributions of the self-assembled structures were determined at these conditions by dynamic light scattering. Figure 7 exemplifies the correlation function of a 1 wt \% nondialyzed $\mathrm{CN}$ solution at $20^{\circ} \mathrm{C}$. To assess whether multiple scattering effects may have influenced the measured particle size distribution, measurements in cross-correlation mode (instrument 2) were also performed. To make the results comparable, correlation functions were normalized. For this purpose, the correlation at the first lag time was set to $100 \%$, whereas other values were calculated proportionally. The correlation functions had the typical shapes as described elsewhere (de Kruif and Grinberg, 2002; Nash et al., 2002; HadjSadok et al., 2008). The shape of the cross-correlation did not differ from that of the autocorrelation function. One can thus conclude that multiple scattering was not interfering with the measurements. The correlation functions determined with instrument 1 decreased earlier to zero than the measurements with instrument 2 . This was likely due to differences between the instruments. Figure 7 also shows the particle size distribution, which was then calculated from the correlation function by the general purpose mode algorithm implemented in the software package of instrument 1 and by CONTIN (inverse Laplace transformation) as implemented in the software package of instrument 2 . The measurements reveal a multimodal particle size distribution. The second peak corresponded to a mean diameter of $200 \mathrm{~nm}$ and was reproducible on both instruments as well as in auto- and cross-correlation. The first peak related to $20 \mathrm{~nm}$ was only observed with instrument 1 . The first peak also appeared in measurements with instrument 2 in autoas well as cross-correlation mode, but it was not reproducible. As seen in Figure 7, the first peak determined with instrument 1 was broad and the peaks of the other 2 measurements fell within this peak. The software of instrument 1 and 2 differ in the way they calculate the distribution: instrument 1 averages several correlation functions and then calculates the distribution, whereas instrument 2 calculates the distribution from a single correlation function. As a consequence, the first peak was not reproducible by both instruments. Moreover, although it seemed reproducible in instrument 1 , the 
reproducibility was likely only caused by the averaging of the correlation functions by the software.

Particle sizes in the 1-phase region determined with instrument 1 for concentrations between 0.01 to $1 \mathrm{wt}$ $\%$ and temperatures between 20 to $50^{\circ} \mathrm{C}$ are listed in Appendix Table A2. No differences between dialyzed
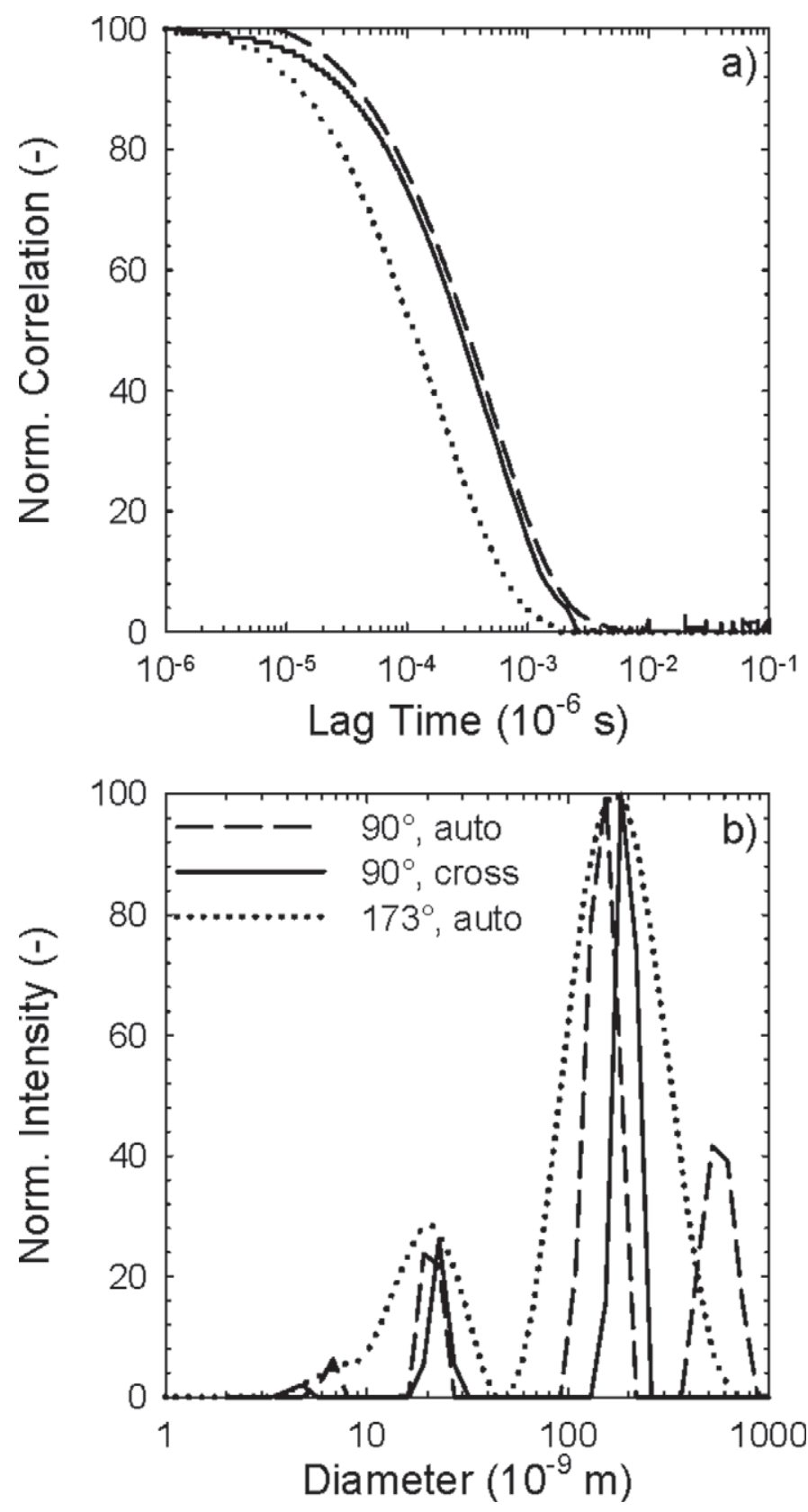

Figure 7. Correlation function (a) and particle size distribution (b) of a nondialyzed CN solution with a concentration of $1 \mathrm{wt} \%$ measured at $173^{\circ}$ in autocorrelation with instrument 1 (Zetasizer Nano Series; Malvern Instruments $\mathrm{GmbH}$, Herrenberg, Germany) and at $90^{\circ}$ in auto- and cross-correlation with instrument 2 (3D LS Spectrometer Pro; LS Instruments AG, Fribourg, Switzerland). One representative measurement is shown. Norm. = normalized. and nondialyzed samples, by different amounts of ions in solution counterbalancing the charges at the protein, were observed. Due to the fact that the surface properties as well as the cloud points were influenced by dialysis, the results obtained by light scattering are questionable.

In the literature, particle size distributions determined by dynamic light scattering of $\beta$-CN or sodium caseinates have been described as being monomodal (Belyakova et al., 2003; Dauphas et al., 2005; Gangnard et al., 2007), bimodal (Chu et al., 1995; de Kruif and Grinberg, 2002; Nash et al., 2002; HadjSadok et al., 2008), and multimodal (Boulet et al., 2000; Semenova et al., 2009). The hydrodynamic diameter was around $20 \mathrm{~nm}$ for the small structures and around $200 \mathrm{~nm}$ for the big structures in the case of the bimodal distributions, whereas in the case of monomodal distributions, either small aggregates (Dauphas et al., 2005; Gangnard et al., 2007) or large aggregates (Belyakova et al., 2003) were observed.

We conclude from these measurements that dynamic light scattering is not an appropriate method to determine particle size distributions of the self-assembled CN. Therefore, FFEM was used to visualize aggregate formation. Indeed, self-assembled structures with a diameter ranging between 15 and $30 \mathrm{~nm}$ could be observed in a nondialyzed 1 wt \% solution (results not shown), confirming that self-assembled structures were present.

\section{CONCLUSIONS}

The study examined the properties of a food-grade $\alpha_{\mathrm{s}}-\mathrm{CN}$ at the water-air surface as well as in solution. Remarkable influences could be observed by reducing the amount of counterions using a dialysis step, which increased the repulsive electrostatic interactions between and within the CN. As a consequence, the $\mathrm{CMC}$ and $A_{\min }$ increased similar to the behavior of classical ionic surfactants. In addition, the removal of ions may also influence the adsorption process and change the secondary structure, as shown schematically in Figure 8. The cloud point decreased after dialysis for all examined concentrations, indicating that the sum of the molecular interactions was altered. The particle size distribution was determined by dynamic light scattering in auto- and cross-correlation mode, but both methods appeared to not be suitable for the CN system. Ultra small-angle neutron scattering (USANS) or multi-angle laser scattering (MALS) might be more suitable methods to determine the particle size distribution of the self-assembled structures. The presence of structures with a diameter of 15 to $30 \mathrm{~nm}$ was, however, confirmed by FFEM. 
on the surface in solution microscopic
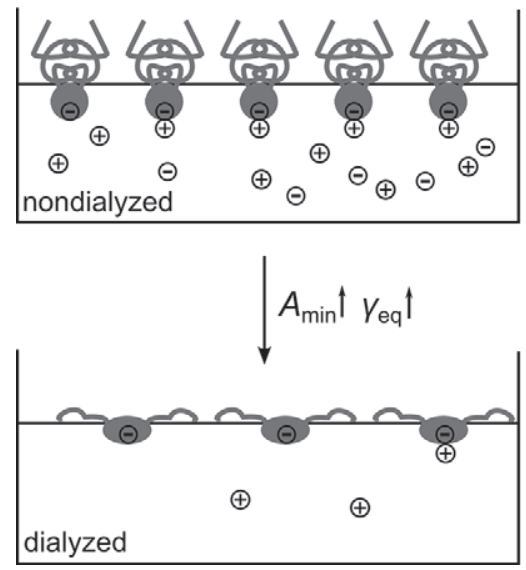
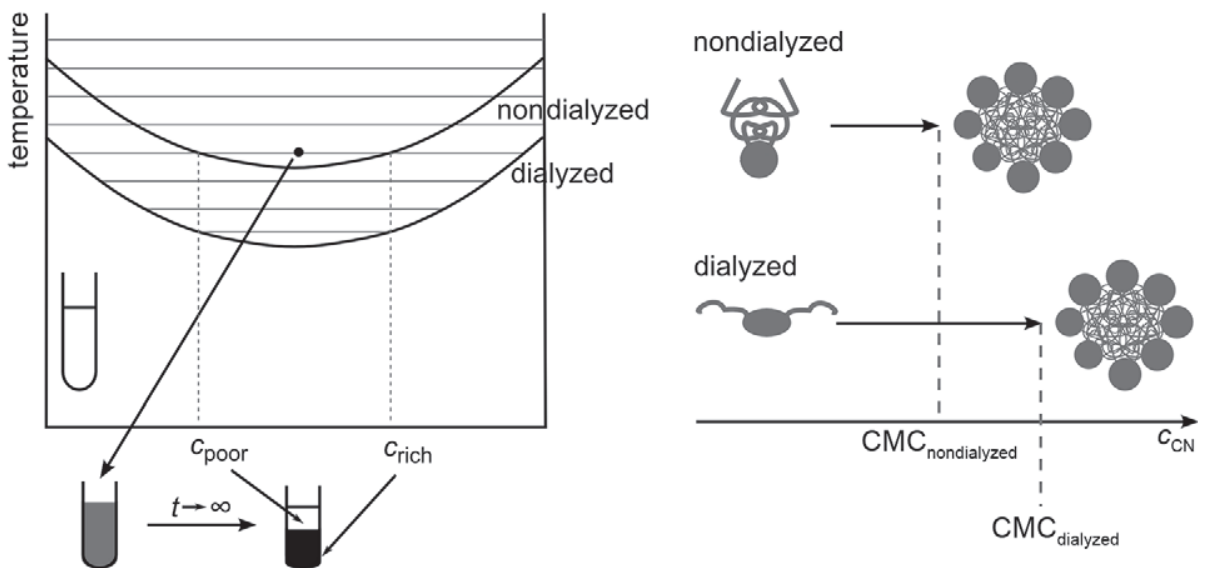

Figure 8. Schematic diagram of temperature-dependent phase behavior of nondialyzed and dialyzed $\alpha_{\mathrm{s}}$-CN based on surface tension and cloud point measurements. $A_{\min }=$ minimum surface area; $\gamma_{\text {eq }}=$ equilibrium surface tension; $c=$ concentration; $t=$ time; CMC $=$ critical micelle concentration.

Our results show therefore that our food-grade $\alpha_{\mathrm{s}}$ $\mathrm{CN}$ was able to form self-assembled structures that may be suitable vehicles to encapsulate hydrophobic compounds (e.g., vitamin D). Using the $\alpha_{\mathrm{s}}-\mathrm{CN}$ as raw material, an encapsulation might be performed in situ. This is in contrast to studies with CN micelles, where substantial chemical or mechanical action is needed to load them with function compounds. In ongoing studies, we are focusing on aggregation properties of $\alpha_{\mathrm{s}}-\mathrm{CN}$ in combination with an additional block copolymer to potentially reduce temperature sensitivity of the system, which is a disadvantage for usage in food systems. Additionally, encapsulation properties of the examined systems are being evaluated to show a potential usage. Furthermore, a comparison between a standard caseinate and our fractionated $\alpha_{\mathrm{s}}$-CN-rich fraction should be performed to determine whether the increased costs of generating such an enriched fraction is offset by enhanced functionalities such as, for example, improved stabilization of foams or emulsions. Due to the fact that acids and bases and, therefore, ions are added during the fractionation, and that their influence as shown in this study is considerable, such studies should, however, be conducted on $\mathrm{CN}$ having similar counterbalanced charges so as to distinguish between the effects of an enrichment with $\alpha_{\mathrm{s}}$-CN and an enrichment in counterbalancing ions. The results shown should, therefore, be of interest to food scientists both in academia and industry. The fractionation of a fully food-grade functional class of $\mathrm{CN}$ may enhance the value of raw materials and bring new functionalities to a wide variety of foods.

\section{ACKNOWLEDGMENTS}

We sincerely thank Aline Holder and Antonie Post (both from the University of Hohenheim, Stuttgart, Germany) for their aid and invaluable help in the HPLC analysis and the protein fractionation. Our further appreciation goes to Julia Boos (Universität Stuttgart, Stuttgart, Germany) for her support of the surface tension measurements, Enda Carey (Universität Stuttgart) for his help in establishing the phase diagrams, Sandra Engelskirchen (Universität Stuttgart) in conducting the cross-DLS measurement, Natalie Preisig (Universität Stuttgart) in conducting the FFEM imaging experiments, and Hannes Kurz (Landesanstalt für landwirtschaftliche Chemie, Stuttgart, Germany) for realizing the mineral analysis. This research project was supported financially by the Experiment Station of the University of Hohenheim (Stuttgart, Germany) and by the German Ministry of Economics and Technology (Berlin, Germany; via AiF e.V., Köln, Germany) and the Forschungskreis der Ernährungsindustrie e.V. (FEI; Bonn, Germany; Project AiF 16541).

\section{REFERENCES}

Asherie, N. 2004. Protein crystallization and phase diagrams. Methods $34: 266-272$.

Bachar, M., A. Mandelbaum, I. Portnaya, H. Perlstein, S. Even-Chen, Y. Barenholz, and D. Danino. 2012. Development and characterization of a novel drug nanocarrier for oral delivery, based on selfassembled $\beta$-casein micelles. J. Control. Release 160:164-171.

Beaufils, S., R. Hadaoui-Hammoutène, V. Vié, G. Miranda, J. Perez, E. Terriac, G. Henry, M.-M. Delage, J. Léonil, P. Martin, and A. Renault. 2007. Comparative behaviour of goat $\beta$ and $\alpha_{s 1}$-caseins at 
the air-water interface and in solution. Food Hydrocoll. 21:13301343.

Belyakova, L. E., A. S. Antipova, M. G. Semenova, E. Dickinson, L. M. Merino, and E. N. Tsapkina. 2003. Effect of sucrose on molecular and interaction parameters of sodium caseinate in aqueous solution: Relationship to protein gelation. Colloids Surf. B Biointerfaces $31: 31-46$.

Boulet, M., M. Britten, and F. Lamarche. 2000. Aggregation of some food proteins in aqueous dispersions: Effects of concentration, $\mathrm{pH}$ and ionic strength. Food Hydrocoll. 14:135-144.

Burauer, S., L. Belkoura, C. Stubenrauch, and R. Strey. 2003. Bicontinuous microemulsions revisited: A new approach to freeze fracture electron microscopy (FFEM). Colloids Surf. A Physicochem. Eng. Asp. 228:159-170.

BVL. 1980. Amtliche Sammlung von Untersuchungsverfahren nach §35 Lebensmittel- und Bedarfsgegenständegesetz (LMBG) L06.004. Untersuchung von Lebensmitteln. Bestimmung der Asche in Fleisch und Fleischerzeugnissen. Beuth Verlag GmbH, Berlin, Germany.

Caessens, P. W., H. H. De Jongh, W. Norde, and H. Gruppen. 1999a The adsorption-induced secondary structure of $\beta$-casein and of distinct parts of its sequence in relation to foam and emulsion properties. Biochim. Biophys. Acta 1430:73-83.

Caessens, P. W. J. R., H. Gruppen, S. Visser, G. A. van Aken, and A G. J. Voragen. 1997. Plasmin hydrolysis of $\beta$-casein: Foaming and emulsifying properties of the fractionated hydrolysate. J. Agric. Food Chem. 45:2935-2941.

Caessens, P. W. J. R., S. Visser, H. Gruppen, G. A. van Aken, and A. G. J. Voragen. 1999b. Emulsion and foam properties of plasmin derived $\beta$-casein peptides. Int. Dairy J. 9:347-351.

Chu, B., Z. Zhou, G. Wu, and H. M. Farrell Jr.. 1995. Laser light scattering of model casein solutions: Effects of high temperature. J. Colloid Interface Sci. 170:102-112.

Ciferri, A. 2008. Charge-dependent and charge-independent contributions to ion-protein interaction. Biopolymers 89:700-709.

Creamer, L. 2004. Milk proteins - Casein nomenclature, structure and association Properties. Pages 1895-1902 in Encyclopedia of Dairy Science. H. Roginski, ed. Academic Press, Amsterdam, the Netherlands

Dauphas, S., N. Mouhous-Riou, B. Metro, A. R. Mackie, P. J. Wilde, M. Anton, and A. Riaublanc. 2005. The supramolecular organisation of $\beta$-casein: Effect on interfacial properties. Food Hydrocoll. 19:387-393.

de Kruif, C. G., and V. Y. Grinberg. 2002. Micellisation of $\beta$-casein. Colloids Surf. A Physicochem. Eng. Asp. 210:183-190.

Dickinson, E., and M. Golding. 1998. Influence of alcohol on stability of oil-in-water emulsions containing sodium caseinate. J. Colloid Interface Sci. 197:133-141.

Dickinson, E., D. S. Horne, V. J. Pinfield, and F. A. M. Leermakers. 1997a. Self-consistent-field modelling of casein adsorption. Comparison of results for $\alpha_{s 1}$-casein and $\beta$-casein. J. Chem. Soc. Faraday Trans. 93:425-432.

Dickinson, E., V. J. Pinfield, D. S. Horne, and F. A. M. Leermakers. 1997b. Self-consistent-field modelling of adsorbed casein: Interaction between two protein-coated surfaces. J. Chem. Soc. Faraday Trans. 93:1785-1790.

Euston, S. R., and D. S. Horne. 2005. Simulating the self-association of caseins. Food Hydrocoll. 19:379-386.

Evans, M. T. A., J. R. Mitchell, P. R. Mussellwhite, and L. Irons, 1970. The effect of the modification of protein structure on the properties of proteins spread and adsorbed at the air-water interface. Adv. Exp. Med. Biol. 7:1-22.

Fox, P. 2003. Milk proteins: General and historical aspects. Pages 1-47 in Advanced Dairy Chemistry Volume 1: Proteins. P. F. Fox and P. L. H. McSweeney, ed. Elsevier, London, UK.

Gangnard, S., Y. Zuev, J.-C. Gaudin, V. Fedotov, Y. Choiset, M. A. V. Axelos, J.-M. Chobert, and T. Haertlé. 2007. Modifications of the charges at the $\mathrm{N}$-terminus of bovine $\beta$-casein: Consequences on its structure and its micellisation. Food Hydrocoll. 21:180-190.
Gažová, Z., M. Antalík, J. Bágel'ová, and Z. Tomori. 1999. Effect of ionic strength on the interfacial properties of Cytochrome c. Biochim. Biophys. Acta 1432:82-91.

Gibis, M., E. Vogt, and J. Weiss. 2012. Encapsulation of polyphenolic grape seed extract in polymer-coated liposomes. Food Funct. 3:246-254. http://dx.doi.org/10.1039/C1FO10181A

Grigsby, J. J., H. W. Blanch, and J. M. Prausnitz. 2001. Cloud-point temperatures for lysozyme in electrolyte solutions: Effect of salt type, salt concentration and pH. Biophys. Chem. 91:231-243.

Guilloteau, J.-P., M. M. Riès-Kautt, and A. F. Ducruix. 1992. Variation of lysozyme solubility as a function of temperature in the presence of organic and inorganic salts. J. Cryst. Growth 122:223-230.

HadjSadok, A., A. Pitkowski, T. Nicolai, L. Benyahia, and N. MoulaiMostefa. 2008. Characterisation of sodium caseinate as a function of ionic strength, $\mathrm{pH}$ and temperature using static and dynamic light scattering. Food Hydrocoll. 22:1460-1466.

Haham, M., S. Ish-Shalom, M. Nodelman, I. Duek, E. Segal, M Kustanovich, and Y. D. Livney. 2012. Stability and bioavailability of Vitamin D nanoencapsulated in casein micelles. Food Funct. 3:737-744.

Harkins, W. D., and H. F. Jordan. 1930. Surface tension by the ring method. Science 72:73-75.

Hiemenz, P. C., and R. Rajagopalan. 1997. Principles of Colloid and Surface Chemistry. Taylor \& Francis Group, Boca Raton, FL.

Holt, C., and S. Lindsay. 1993. Caseins as rheomorphic proteins: Interpretation of primary and secondary structure of $\alpha_{s 1}, \beta$ - and к-caseins. J. Chem. Soc. Faraday Trans. 89:2683-2692.

Horne, D. S. 2002. Casein structure, self-assembly and gelation. Curr. Opin. Colloid Interface Sci. 7:456-461.

Kotsmar, C., D. O. Grigoriev, F. Xu, E. V. Aksenenko, V. B. Fainerman, M. E. Leser, and R. Miller. 2008. Equilibrium of adsorption of mixed milk protein/surfactant solutions at the water/air interface. Langmuir 24:13977-13984.

Krägel, J., R. Wüstneck, F. Husband, P. J. Wilde, A. V. Makievski, D. O. Grigoriev, and J. B. Li. 1999. Properties of mixed protein/surfactant adsorption layers. Colloids Surf. B Biointerfaces 12:399-407.

Kunz, W. 2010. Specific ion effects in colloidal and biological systems. Curr. Opin. Colloid Interface Sci. 15:34-39.

Kunz, W., J. Henle, and B. W. Ninham. 2004. 'Zur Lehre von der Wirkung der Salze' (about the science of the effect of salts): Franz Hofmeister's historical papers. Curr. Opin. Colloid Interface Sci 9:19-37.

Latnikova, A. V., S.-Y. Lin, G. Loglio, R. Miller, and B. A. Noskov. 2008. Impact of surfactant additions on dynamic properties of $\beta$-casein adsorption layers. J. Phys. Chem. C 112:6126-6131.

Laughlin, R. G. 1994. The Aqueous Phase Behavior of Surfactants. Academic Press, London, UK.

Lide, D. R. 2003. CRC Handbook of Chemistry and Physics. CRC Press, Boca Raton, FL.

Livney, Y. D. 2010. Milk proteins as vehicles for bioactives. Curr. Opin. Colloid Interface Sci. 15:73-83.

Lu, J., K. Carpenter, R.-J. Li, X.-J. Wang, and C.-B. Ching. 2004. Cloud-point temperature and liquid-liquid phase separation of supersaturated lysozyme solution. Biophys. Chem. 109:105-112.

Makievski, A. V., R. Wüstneck, D. O. Grigoriev, J. Krägel, and D. V. Trukhin. 1998. Protein adsorption isotherms studied by axisymmetric drop shape analysis. Colloids Surf. A Physicochem. Eng. Asp. 143:461-466.

Menéndez, O., U. Schwarzenbolz, C. Partschefeld, and T. Henle. 2009 Affinity of microbial transglutaminase to $\alpha_{s 1^{-}}, \beta-$, and acid casein under atmospheric and high pressure conditions. J. Agric. Food Chem. 57:4177-4184.

Menéndez-Aguirre, O., W. Stuetz, T. Grune, A. Kessler, J. Weiss, and J. Hinrichs. 2011. High pressure-assisted encapsulation of vitamin $\mathrm{D}_{2}$ in reassembled casein micelles. High Press. Res. 31:265-274.

Mezdour, S., G. Brulé, and J. Korolczuk. 2006. Physicochemical analysis of casein solubility in water-ethanol solutions. Lait 86:435-452.

Mizuno, R., and J. A. Lucey. 2005. Effects of emulsifying salts on the turbidity and calcium-phosphate-protein interactions in casein micelles. J. Dairy Sci. 88:3070-3078. 
Mohanty, B., D. M. Mulvihill, and P. F. Fox. 1988. Emulsifying and foaming properties of acidic caseins and sodium caseinate. Food Chem. 28:17-30.

Mukherjee, P., S. K. Padhan, S. Dash, S. Patel, and B. K. Mishra. 2011. Clouding behaviour in surfactant systems. Adv. Colloid Interface Sci. $162: 59-79$.

Myers, D. 2006. Surfactant Science and Technology. Wiley-VCH, Hoboken, NJ.

Nash, W., D. N. Pinder, Y. Hemar, and H. Singh. 2002. Dynamic light scattering investigation of sodium caseinate and xanthan mixtures. Int. J. Biol. Macromol. 30:269-271.

Ng-Kwai-Hang, K. F. 2004. Milk proteins-Heterogeneity, fractionation and isolation. Pages 1881-1894 in Encyclopedia of Dairy Science. Academic Press, Amsterdam, the Netherlands.

Park, E. J., and Y. C. Bae. 2004. Cloud-point temperatures of lysozyme in electrolyte solutions by thermooptical analysis technique. Biophys. Chem. 109:169-188.

Portnaya, I., E. Ben-Shoshan, U. Cogan, R. Khalfin, D. Fass, O. Ramon, and D. Danino. 2008. Self-assembly of bovine $\beta$-casein below the isoelectric pH. J. Agric. Food Chem. 56:2192-2198.

Portnaya, I., U. Cogan, Y. D. Livney, O. Ramon, K. Shimoni, M. Rosenberg, and D. Danino. 2006. Micellization of bovine $\beta$-casein studied by isothermal titration microcalorimetry and cryogenic transmission electron microscopy. J. Agric. Food Chem. 54:55555561.

Post, A. E., M. Ebert, and J. Hinrichs. 2009. $\beta$-Casein as a bioactive precursor-Processing for purification. Aust. J. Dairy Technol. 64:84-88.

Post, A. E., and J. Hinrichs. 2011. Large-scale isolation of food-grade $\beta$-casein. Milchwissenschaft 66:361-364.

Post, A. E. P., B. Arnold, J. Weiss, and J. Hinrichs. 2012. Effect of temperature and $\mathrm{pH}$ on the solubility of caseins: II. Environmental influences on the dissociation of $\alpha_{s^{-}}$and $\beta$-casein. J. Dairy Sci. 95:1603-1616.

Ries-Kautt, M. M., and A. F. Ducruix. 1989. Relative effectiveness of various ions on the solubility and crystal growth of lysozyme. J. Biol. Chem. 264:745-748.

Rodríguez Patino, J. M., M. R. Rodríguez Niño, and C. Carrera Sánchez. 2003. Structure, miscibility, and rheological characteristics of $\beta$-casein-monoglyceride mixed films at the air-water interface. J. Agric. Food Chem. 51:112-119.

Rodríguez Patino, J. M., M. C. Fernández, M. R. Rodríguez Niño, and C. C. Sánchez. 2006a. Spreading of monoglycerides onto $\beta$-casein adsorbed film. Structural and dilatational characteristics. J. Agric. Food Chem. 54:3723-3732.

Rodríguez Patino, J. M., M. C. Fernández, C. C. Sánchez, and M. R. Rodríguez Niño. 2006b. Structural and shear characteristics of adsorbed $\beta$-casein and monoglyceride mixed monolayers at the air/ water interface. Ind. Eng. Chem. Res. 45:1886-1895.

Rouimi, S., C. Schorsch, C. Valentini, and S. Vaslin. 2005. Foam stability and interfacial properties of milk protein-surfactant systems. Food Hydrocoll. 19:467-478. http://dx.doi.org/10.1016/j.foodhyd.2004.10.032

Sahu, A., N. Kasoju, and U. Bora. 2008. Fluorescence study of the curcumin-casein micelle complexation and its application as a drug nanocarrier to cancer cells. Biomacromolecules 9:2905-2912.

Sánchez, C. C., M. R. Rodríguez Niño, and J. M. Rodríguez Patino. 2005. Dynamic phenomena in caseinate-monoglyceride mixed films at the air-water interface. Food Hydrocoll. 19:395-405.

Sánchez, C. C., M. C. Fernández, M. R. R. Rodríguez Niño, and J. M. Rodríguez Patino. 2006. Thermodynamic and dynamic characteristics of monoglyceride monolayers penetrated by $\beta$-casein. Langmuir 22:4215-4224.

Schulze-Schlarmann, J., N. Buchavzov, and C. Stubenrauch. 2006. A disjoining pressure study of foam films stabilized by tetradecyl trimethyl ammonium bromide $\mathrm{C}_{14} \mathrm{TAB}$. Soft Matter 2:584-594.
Semenova, M. G., L. E. Belyakova, Y. N. Polikarpov, A. Antipova, and E. Dickinson. 2009. Light scattering study of sodium caseinate + dextran sulfate in aqueous solution: Relationship to emulsion stability. Food Hydrocoll. 23:629-639.

Semo, E., E. Kesselman, D. Danino, and Y. D. Livney. 2007. Casein micelle as a natural nano-capsular vehicle for nutraceuticals. Food Hydrocoll. 21:936-942. http://dx.doi.org/10.1016/j.foodhyd.2006.09.006.

Shapira, A., Y. G. Assaraf, D. Epstein, and Y. D. Livney. 2010a. $\beta$-Casein nanoparticles as an oral delivery system for chemotherapeutic drugs: Impact of drug structure and properties on co-assembly. Pharm. Res. 27:2175-2186.

Shapira, A., Y. G. Assaraf, and Y. D. Livney. 2010b. $\beta$-Casein nanovehicles for oral delivery of chemotherapeutic drugs. Nanomedicine 6:119-126.

Shapira, A., I. Davidson, N. Avni, Y. G. Assaraf, and Y. D. Livney. 2012. $\beta$-Casein nanoparticle-based oral drug delivery system for potential treatment of gastric carcinoma: Stability, target-activated release and cytotoxicity. Eur. J. Pharm. Biopharm. 80:298-305.

Shapira, A., G. Markman, Y. G. Assaraf, and Y. D. Livney. 2010c. $\beta$-Casein-based nanovehicles for oral delivery of chemotherapeutic drugs: Drug-protein interactions and mitoxantrone loading capacity. Nanomedicine 6:547-555.

Swaisgood, H. E. 2003. Chemistry of caseins. Pages 139-201 in Advanced Dairy Chemistry Volume 1: Proteins. Elsevier, London, UK

Terjung, N., M. Löffler, M. Gibis, J. Hinrichs, and J. Weiss. 2012. Influence of droplet size on the efficacy of oil-in-water emulsions loaded with phenolic antimicrobials. Food Funct. 3:290-301.

Teubner, M. 1981. The motion of charged colloidal particles in electric fields. J. Chem. Phys. 76:5564-5573.

Tripp, B. C., J. J. Magda, and J. D. Andrade. 1995. Adsorption of globular proteins at the air/water interface as measured via dynamic surface tension: Concentration dependence, mass-transfer considerations, and adsorption kinetics. J. Colloid Interface Sci. 173:16-27.

VDLUFA. 2011a. Handbuch der landwirtschaftlichen Versuchs- und Untersuchungsmethodik (Methodenbuch). Band VII. Umweltanalytik. Bestimmung von ausgewählten Elementen in pflanzlichem Material und in Futtermitteln mit ICP-OES. VDLUFA-Verlag, Darmstadt, Germany.

VDLUFA. 2011b. Handbuch der landwirtschaftlichen Versuchs- und Untersuchungsmethodik (Methodenbuch). Band VII. Umweltanalytik. Bestimmung von Nitrat in pflanzlichem Material mittels Ionenchromatographie (IC). VDLUFA-Verlag, Darmstadt, Germany.

Vieira, C. R., E. A. B. Biasutti, M. Capobiango, W. O. Afonso, and M. P. C. Silvestre. 2006. Effect of salt on the solubility and emulsifying properties of casein and its tryptic hydrolysates. Ars Pharmaceutica 47:281-292.

Walstra, P. 2003. Physical Chemistry of Foods. Marcel Dekker, New York, NY.

Ye, A., M. Srinivasan, and H. Singh. 2000. Influence of $\mathrm{NaCl}$ addition on the properties of emulsions formed with commercial calcium caseinate. Food Chem. 69:237-244.

Ye, A., P. J. B. Edwards, J. Gilliland, G. B. Jameson, and H. Singh. 2012. Temperature-dependent complexation between sodium caseinate and gum arabic. Food Hydrocoll. 26:82-88.

Zar, J. H. 1999. Biostatistical Analysis. Prentice Hall, Upper Saddle River, NY

Zeeb, B., L. Fischer, and J. Weiss. 2011. Cross-linking of interfacial layers affects the salt and temperature stability of multilayered emulsions consisting of fish gelatin and sugar beet pectin. J. Agric. Food Chem. 59:10546-10555.

Zeeb, B., M. Gibis, L. Fischer, and J. Weiss. 2012. Crosslinking of interfacial layers in multilayered oil-in-water emulsions using laccase: Characterization and pH-stability. Food Hydrocoll. 27:126-136. 


\section{APPENDIX}

Table A1. Parameters of the linear function $A(c)=m \cdot c+b$ fitting the linear relationship between adsorption $(A)$ and concentration $(c)$ of the nondialyzed $\mathrm{CN}$ at the temperature $\vartheta ; m$ is the slope and $b$ the intercept of the linear function. The coefficient of determination $\left(\mathrm{R}^{2}\right)$ is given as parameter for the quality of the fit ${ }^{1}$

\begin{tabular}{lccc}
\hline$\vartheta\left({ }^{\circ} \mathrm{C}\right)$ & $m$ & $b$ & $\mathrm{R}^{2}$ \\
\hline 10 & 0.3276 & 0.0140 & 0.98 \\
20 & 0.3190 & 0.0136 & 0.98 \\
30 & 0.3054 & 0.0169 & 0.98 \\
40 & 0.2881 & 0.0211 & 0.97 \\
\hline
\end{tabular}

${ }^{1}$ Measurements were replicated 6 times at 7 concentrations; absorbance measurement performed at a wavelength of $400 \mathrm{~nm}$.

Table A2. Hydrodynamic diameter $\left(d_{h 1}\right.$ and $\left.d_{h 2}\right)$ of structures formed in nondialyzed and dialyzed $\mathrm{CN}$ solutions at pH 6.6 with different concentrations $(c)$ as a function of temperature ${ }^{1}$

\begin{tabular}{|c|c|c|c|c|c|c|c|c|}
\hline$c($ wt $\%)$ & \multicolumn{2}{|c|}{$20^{\circ} \mathrm{C}$} & \multicolumn{2}{|r|}{$30^{\circ} \mathrm{C}$} & \multicolumn{2}{|r|}{$40^{\circ} \mathrm{C}$} & \multicolumn{2}{|c|}{$50^{\circ} \mathrm{C}$} \\
\hline 0.01 & $142 \pm 4^{\mathrm{AB}, \mathrm{a}, \mathrm{I}}$ & $23 \pm 4^{\mathrm{a}, \mathrm{I}}(\mathrm{NR})^{2}$ & $145 \pm 3^{\mathrm{AB}, \mathrm{a}, \mathrm{I}}$ & $20 \pm 5^{\mathrm{A}, \mathrm{a}, \mathrm{I}}(\mathrm{NR})$ & $142 \pm 3^{\mathrm{A}, \mathrm{a}, \mathrm{I}}$ & $20 \pm 7^{\mathrm{A}, \mathrm{a}, \mathrm{I}}(\mathrm{NR})$ & $\vartheta>\vartheta_{\mathrm{cp}}$ & $\vartheta>\vartheta_{\mathrm{cp}}$ \\
\hline 0.05 & $148 \pm 5^{\mathrm{ABC}, \mathrm{a}, \mathrm{I}}$ & $14 \pm 5^{\mathrm{A}, \mathrm{a}, \mathrm{I}}$ & $145 \pm 8^{\mathrm{AB}, \mathrm{a}, \mathrm{I}}$ & $21 \pm 8^{\mathrm{A}, \mathrm{a}, \mathrm{I}}(\mathrm{NR})$ & $\vartheta>\vartheta_{\mathrm{cp}}{ }^{3}$ & $\vartheta>\vartheta_{\mathrm{cp}}$ & $\vartheta>\vartheta_{\mathrm{cp}}$ & $\vartheta>\vartheta_{\mathrm{cp}}$ \\
\hline 0.1 & $159 \pm 11^{\mathrm{ABC}, \mathrm{a}, \mathrm{I}}$ & $21 \pm 7^{\mathrm{A}, \mathrm{a}, \mathrm{I}}$ & $159 \pm 13^{\mathrm{ABC}, \mathrm{a}}$ & $21 \pm 9^{\mathrm{A}, \mathrm{a}}$ & $\vartheta>\vartheta_{\mathrm{cp}}$ & $\vartheta>\vartheta_{\text {cp }}$ & $\vartheta>\vartheta_{\mathrm{cp}}$ & $\vartheta>\vartheta_{\mathrm{cp}}$ \\
\hline 1 & $211 \pm 14^{\mathrm{EF}, \mathrm{a}, \mathrm{I}}$ & $20 \pm 4^{\mathrm{A}, \mathrm{a}, \mathrm{I}}$ & $370 \pm 50^{\mathrm{D}, \mathrm{a}, \mathrm{I}}$ & $20 \pm 4^{\mathrm{A}, \mathrm{a}, \mathrm{I}}$ & $193 \pm 5^{\mathrm{C}, \mathrm{a}}$ & $22 \pm 1.6^{\mathrm{A}, \mathrm{a}}$ & $193 \pm 6^{\mathrm{B}, \mathrm{a}}$ & $25 \pm 2^{\mathrm{B}, \mathrm{a}}$ \\
\hline \multicolumn{9}{|c|}{ Dialyzed CN } \\
\hline 0.01 & $145 \pm 5^{\mathrm{AB}, \mathrm{a}, \mathrm{I}, \mathrm{I}}$ & $18 \pm 6^{\mathrm{A}, \mathrm{a}, \mathrm{I}}(\mathrm{NR})$ & $145 \pm 4^{\mathrm{A}, \mathrm{a}, \mathrm{I}}$ & $23 \pm 7^{\mathrm{A}, \mathrm{a}, \mathrm{I}}(\mathrm{NR})$ & $143 \pm 6^{\mathrm{a}, \mathrm{I}}$ & $24 \pm 9^{\mathrm{a}, \mathrm{I}}(\mathrm{NR})$ & $\vartheta>\vartheta_{\mathrm{cp}}$ & $\vartheta>\vartheta_{\mathrm{cp}}$ \\
\hline 0.05 & $159 \pm 8^{\mathrm{ABC}, \mathrm{a}, \mathrm{I}}$ & $22 \pm 10^{\mathrm{A}, \mathrm{a}, \mathrm{I}^{\mathrm{I}}}(\mathrm{NR})$ & $163 \pm 7^{\mathrm{B}, \mathrm{a}, \mathrm{II}}$ & $21 \pm 6^{\mathrm{A}, \mathrm{a}, \mathrm{I}}$ & $\vartheta>\vartheta_{\mathrm{cp}}$ & $\vartheta>\vartheta_{\mathrm{cp}}$ & $\vartheta>\vartheta_{\mathrm{cp}}$ & $\vartheta>\vartheta_{\mathrm{cp}}$ \\
\hline 0.1 & $157 \pm 9^{\mathrm{BC}, \mathrm{a}, \mathrm{I}}$ & $18 \pm 4^{\mathrm{A}, \mathrm{a}, \mathrm{I}}$ & $\vartheta>\vartheta_{\mathrm{cp}}$ & $\vartheta>\vartheta_{\mathrm{cp}}$ & $\vartheta>\vartheta_{\mathrm{cp}}$ & $\vartheta>\vartheta_{\mathrm{cp}}$ & $\vartheta>\vartheta_{\mathrm{cp}}$ & $\vartheta>\vartheta_{\mathrm{cp}}$ \\
\hline 0.5 & $172 \pm 16^{\mathrm{D}, \mathrm{I}}$ & $21 \pm 4^{\mathrm{A}, \mathrm{I}}(\mathrm{NR})$ & $\vartheta>\vartheta_{\mathrm{cp}}$ & $\vartheta>\vartheta_{\mathrm{cp}}$ & $\vartheta>\vartheta_{\mathrm{cp}}$ & $\vartheta>\vartheta_{\mathrm{cp}}$ & $\vartheta>\vartheta_{\mathrm{cp}}$ & $\vartheta>\vartheta_{\mathrm{cp}}$ \\
\hline
\end{tabular}

${ }_{\mathrm{A}-\mathrm{F}}$ Means with different capital letters as superscripts indicate differences between concentrations at the same temperature $(\alpha=0.05)$.

${ }^{\mathrm{a}, \mathrm{b}}$ Means with different lowercase letters as superscripts indicate differences between temperatures at the same concentration $(\alpha=0.05)$.

${ }^{\mathrm{I}, \mathrm{II}}$ Means with different roman numerals as superscripts indicate differences between dialyzed/nondialyzed sample at the same concentration and temperature $(\alpha=0.05)$.

${ }^{1}$ Measured by dynamic light scattering at $173^{\circ}$ in autocorrelation mode with instrument 1 (Zetasizer Nano Series; Malvern Instruments GmbH, Herrenberg, Germany); average of 6 measurements $\pm \mathrm{SE}(P=95 \%)$.

${ }^{2} \mathrm{NR}=$ peak not reproducible in repeated measurements.

${ }^{3} \vartheta>\vartheta_{\mathrm{cp}}=$ temperature $(\vartheta)$ is above cloud point temperature $\left(\vartheta_{\mathrm{cp}}\right)$. 